\title{
Managing Non-Homogeneous Information and Experts' Psychological Behavior in Group Emergency Decision Making
}

\author{
Liang Wang ${ }^{1,2}$, Álvaro Labella ${ }^{1}$, Rosa M. Rodríguez ${ }^{3, *}$, Ying-Ming Wang ${ }^{2}$ \\ and Luis Martínez ${ }^{1}$ \\ 1 Department of Computer Science, University of Jaén, 23071 Jaén, Spain; wangliangg322@hotmail.com (L.W.); \\ alabella@ujaen.es (Á.L.); martin@ujaen.es (L.M.) \\ 2 Decision Sciences Institute, Fuzhou University, Fuzhou 350116, China; msymwang@hotmail.com \\ 3 Department of Computer Science and A.I., University of Granada, 18071 Granada, Spain \\ * Correspondence: rosam.rodriguez@decsai.ugr.es
}

Received: 25 September 2017; Accepted: 13 October 2017; Published: 18 October 2017

\begin{abstract}
After an emergency event (EE) happens, emergency decision making (EDM) is a common and effective way to deal with the emergency situation, which plays an important role in mitigating its level of harm. In the real world, it is a big challenge for an individual emergency manager (EM) to make a proper and comprehensive decision for coping with an EE. Consequently, many practical EDM problems drive group emergency decision making (GEDM) problems whose main limitations are related to the lack of flexibility in knowledge elicitation, disagreements in the group and the consideration of experts' psychological behavior in the decision process. Hence, this paper proposes a novel GEDM approach that allows more flexibility for preference elicitation under uncertainty, provides a consensus process to avoid disagreements and considers experts' psychological behavior by using the fuzzy TODIM method based on prospect theory. Eventually, a group decision support system (GDSS) is developed to support the whole GEDM process defined in the proposed method demonstrating its novelty, validity and feasibility.
\end{abstract}

Keywords: group emergency decision making; non-homogeneous information; psychological behavior; group decision support system

\section{Introduction}

Emergencies are defined as events that suddenly take place, causing or having the possibility of provoking intense death and injury, property loss, ecological damage and social hazards. In recent years, various emergency events, such as earthquakes, floods, hurricanes, terrorist attacks, etc., have exerted severely negative impacts on human life and socio-economic development. When an emergency event (EE) occurs, Emergency Decision Making (EDM) is typically characterized by at least uncertainty, time pressure, and lack of information, resulting in potentially serious consequences [1]. Since EDM plays a crucial role in alleviating the losses of properties and lives caused by EEs, it has received increasing attention from both government and academia because of the frequent occurrence of EEs, becoming a very active and important research field in recent years [1-5].

When an EE occurs, it is hard to collect the information related to the event and predict its evolution particularly in the early stage because of the inadequate and uncertain information. Consequently, it is too complex for just one emergency manager (EM) to make comprehensive judgments under emergency situations. Therefore, EDM requires multiple experts from diverse professional backgrounds (such as hydrological, geological, meteorological, sociological, demographic, etc.) to help the EM make a decision. This leads to Group EDM (GEDM) problems. Figure 1 shows 
a graphical general scheme for GEDM problems, in which experts play a role of think tank in supporting the EM who is in charge of the EE.

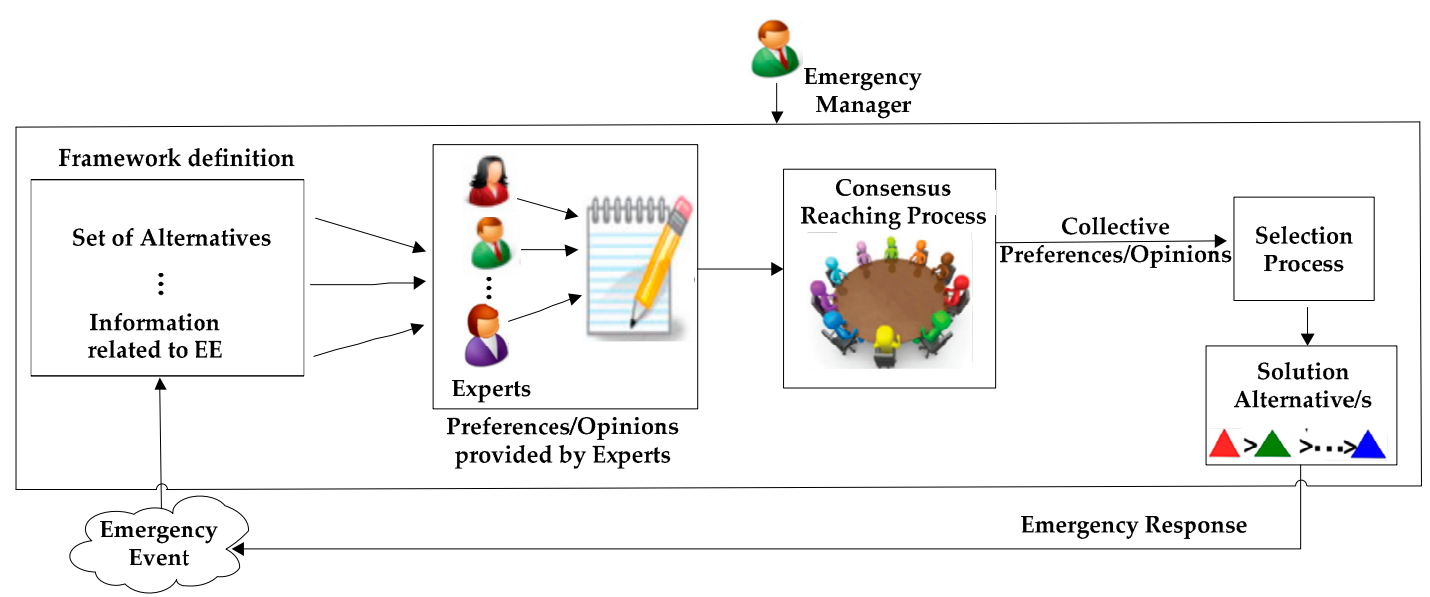

Figure 1. The general scheme of GEDM process.

In the real world, it is common that experts with different background and knowledge might have different attitudes or opinions over different alternatives concerning different criteria. Moreover, criteria defined in a GEDM problem might have different nature, qualitative or quantitative. Therefore, experts might hesitate and express their opinions or assessments by using different types of information according to their knowledge and criteria nature. The complexity of GEDM problems could imply not only the use of a non-homogeneous context in which multiple information types can be utilized by experts to elicit their knowledge and expertise, but also the modeling of uncertain assessments including hesitancy. However, current EDM approaches deal with the information using only one expression domain: numerical values [4], interval values [3] or linguistic information [6].

Traditionally, group decision making (GDM) approaches have shown that a solution can be obtained under disagreement among experts [7,8], however several experts may not accept the decision made because they might consider that their individual opinions have not been taken into account sufficiently $[9,10]$. Such a situation could be very serious in GEDM driving either to deadlock in the decision or in a harmful decision. Hence, it seems necessary and reasonable to achieve a consensus among all experts involved in the GEDM problem before making the decision. The Consensus Reaching Process (CRP) is a way to integrate group wisdom into one and then reach an agreement among all experts in the GEDM problem. There are already different approaches $[1,4,11]$ focused on how to reach as much agreement as possible among all experts participating in the problem. However, they have strict expression domains [1,11]; or time cost [4,5]. However, time is extremely valuable, because it means lives and chances, thus emergency responses cannot afford a time-consuming consensus model.

Different behavioral experiments [12-14] show that human beings are usually bounded rationally in decision-making processes under risk and uncertainty. Therefore, psychological behavior plays a crucial role in the decision processes. Nevertheless, as far as we know, experts' psychological behavior is neglected in current GEDM $[1,4,5,11,15]$ approaches.

According to the previous limitations presented in current GEDM methods, the aim of this paper is to propose a new GEDM method that overcomes them. Such a method is able:

1. To allow more flexibility for eliciting information by dealing with non-homogeneous information including hesitancy.

2. To include a consensus model with low time cost to achieve an agreement among experts involved in the GEDM problem.

3. To take into account experts' psychological behavior by means of the fuzzy TODIM method [16-18] based on prospect theory [14]. 
Furthermore, the proposed method is implemented into a Group Decision Support System (GDSS) named GENESIS (Group EmergeNcy dEcision SupportIng System) based on FLINTSTONES (Fuzzy LINguisTic DeciSion Tools eNhacemEnt Suite) $[19,20]$ that supports the whole GEDM process effectively and in a timely way, as shown in an illustrative example.

The remainder of this paper is organized as follows: Section 2 revises briefly different concepts about non-homogeneous information, CRPs and the fuzzy TODIM, which will be used in our proposal together with some related works. Section 3 presents the new GEDM method that integrates the novelties pointed out previously. Section 4 introduces the structure and components of the GDSS, GENESIS, and shows an example to illustrate the feasibility and validity of the proposed method. A sensitive analysis is also presented to study the robustness of the proposal. Section 5 presents some conclusions and future works.

\section{Preliminaries}

In this section, some basic concepts about non-homogeneous information and CRPs are revised in short in order that readers can understand easily the proposed GEDM model. It also reviews the fuzzy TODIM method that is used in the selection process of the proposal to obtain the ranking of alternatives considering experts' psychological behavior. Eventually, some related works to illustrate the importance of this research are reviewed.

\subsection{Non-Homogeneous Information in Decision Making}

Nowadays, real-world decision-making problems are more diversified and complex because of rapid socio-economic development, such as EDM problems [2,3], GEDM problems [1,15], and Intelligent GEDM problems [11]. Those problems are usually defined under uncertainty because of inadequate and uncertain information. The complexity of these problems implies multiple experts with different backgrounds and knowledge participating in the decision process.

To model the uncertainty and non-homogeneous information, such as numerical values, interval values and linguistic terms elicited by experts, several approaches have been discussed in current GDM approaches. Some of them [21-25] make the computations using directly the non-homogeneous information [26] and others unify the information into one domain [24,27], being the most common one the linguistic information. Recently, the inclusion of hesitancy is becoming more important [28,29].

The concept of hesitant fuzzy linguistic term sets (HFLTS) [30] has been introduced to model experts' hesitation in qualitative settings and it has been applied in decision making problems obtaining successful results. It is defined as follows.

Definition 1 [30]. Let $S=\left\{s_{0}, s_{1}, \ldots, s_{g}\right\}$ be a linguistic term set, a HFLTS $H_{S}$, is defined as an ordered finite subset of consecutive linguistic terms of $S$ :

$$
H_{S}=\left\{s_{i}, s_{i+1}, \ldots, s_{j}\right\}, s_{k} \in S, k \in\{i, \ldots, j\}
$$

Nevertheless, when experts provide their opinions and they feel hesitation among several linguistic terms, they do not use multiple linguistic terms, but linguistic expressions close to the natural language used by human beings. Hence, Rodríguez et al. [30] proposed the use of context-free grammars $G_{H}$ to build complex linguistic expressions more flexible and richer than single linguistic terms $[29,30]$. The expressions produced by the context-free grammar $G_{H}$, may be either a single linguistic term $s_{i} \in S$, or comparative linguistic expressions $S_{l l}$ (see $[29,30]$ for further detail).

In our proposal, the non-homogeneous information including experts' hesitancy will be transformed into a unified fuzzy domain to facilitate the computations (see Section 3.3). 


\subsection{Consensus Reaching Processes}

GDM problems are usually solved by a selection process that obtains the best alternative as a solution to the problem. However, sometimes the goal of the problem is not to obtain the best solution, but an accepted one for all involved experts in the problem. In such a situation, it seems necessary to apply a CRP. Consensus can be defined as [9] "a state of mutual agreement among members of a group in which the decision made satisfies all of them". Therefore, a consensus process requires that experts modify their opinions making them closer to each other and this way to obtain a collective opinion that is satisfactory for all of them [10,31-34].

In GEDM process, experts play a role of think tank in supporting EM to make a decision, recently several proposals $[1,4,5,11,15,34]$ integrate CRP into GEDM to deal with experts' opinions in order to achieve an agreement among all experts involved and make a right decision. However, these approaches deal just with numerical values $[1,5,25]$ and are not suitable for other types of information, additionally, they have a high time cost $[4,5]$ because of the supervised feedback mechanism that should be avoided in GEDM problems.

Due to these reasons and the type of information used in our proposal, a fuzzy linear programming-based consensus model [34] with low time cost will be utilized to achieve consensus in our proposal. Before introducing the fuzzy linear programming model, it is necessary to revise the definition of the distance between fuzzy numbers, which will be used.

Definition 2 [34]. Let $A=\left(a_{1}, a_{2}, a_{3}, a_{4}\right)$ and $B=\left(b_{1}, b_{2}, b_{3}, b_{4}\right)$ be two trapezoidal fuzzy numbers. The distance between $A$ and $B$ can be obtained as follows, the measure of $d_{p}$ can also be called as $l_{p}$ metric:

$$
d_{p}(A, B)=\left(\sum_{i=1}^{4}\left(\left|a_{i}-b_{i}\right|\right)^{p}\right)^{1 / p}
$$

where $p$ is an integer $\geq 1$. Let $U$ be the universe of discourse and $u=\max (U)-\min (U)$. The similarity between $A$ and $B$ can be defined as [34,35]:

$$
S_{p}(A, B)=1-\frac{1}{4 u^{p}}\left(d_{p}(A, B)\right)^{p}
$$

The dissimilarity is defined as $c-S_{p}(A, B)$, where $c$ is a constant $>1$. The selection of $c$ will influence in the final result of the aggregation.

Let $\widetilde{A}_{h}=\left(a_{h 1}, a_{h 2}, a_{h 3}, a_{h 4}\right)$ be the $h$-th expert's individual opinion and $\widetilde{O}$ be the overall opinion obtained by aggregating experts' individual opinions.

The fuzzy linear programming model is [34]:

$$
\left\{\begin{array}{c}
\min \sum_{h=1}^{\bar{K}}\left(w^{h}\right)^{\alpha}\left(c-S_{p}\left(\widetilde{A}_{h}, \widetilde{O}\right)\right) \\
\text { s.t. } d_{p}\left(\widetilde{A}_{h}, \widetilde{O}\right) \leq \varepsilon_{h}, h=1,2, \ldots, \bar{K}
\end{array}\right.
$$

where $\alpha$ is an integer $\geq 1, w^{h}$ denotes the h-th experts' importance. $\varepsilon_{h}$ denotes a threshold that means the maximum change that the $h$-th expert can make. $d_{p}\left(\widetilde{A}_{h}, \widetilde{O}\right)$ denotes the distance between $\widetilde{A}_{h}$ and $\widetilde{O}$, which can be obtained according to Equation (1).

\subsection{Fuzzy TODIM Method}

Some studies [12-14] have shown that human beings are bounded rationally especially in risk and uncertain decision processes and their psychological behavior is very important in the decision process. Therefore, it seems necessary to consider experts' psychological behavior in GEDM problem. 
TODIM method was proposed by Gomes and Lima [36,37]; it is a popular multi-criteria decision making (MCDM) method based on prospect theory [13] considering humans psychological behavior. It has been widely applied to solve different decision problems $[38,39]$. To cope with complex problems and uncertain information in the real world, the TODIM method has been extended to deal with fuzzy MCDM problems [16,17].

In our proposal, we will use fuzzy TODIM method [16-18] based on prospect theory [14] because of its advantage and capability of capturing the experts' psychological behavior under fuzzy environment.

The fuzzy TODIM was introduced in [18] and briefly summarized below:

Let $P=\left\{p_{1}, p_{2}, \ldots, p_{m}\right\}$ be a set of alternatives, $C=\left\{c_{1}, c_{2}, \ldots, c_{n}\right\}$ be a set of criteria and $w_{c}=\left(w_{c_{1}}, w_{c_{2}}, \ldots, w_{c_{n}}\right)$ be a weighting vector for criteria, where $w_{c_{j}}$ denotes the weight of criterion $c_{j}$. Let $A=\left(a_{i j}\right)_{m \times n}$ be a fuzzy decision matrix, where $a_{i j}=\left(a_{i j}^{1}, a_{i j}^{2}, a_{i j}^{3}, a_{i j}^{4}\right)$ denotes the rating of the alternative $p_{i}$ with respect to criterion $c_{j}$.

Step 1: To normalize the fuzzy decision matrix $A=\left(a_{i j}\right)_{m \times n}$ into the correspondent normalized fuzzy decision matrix $G=\left(g_{i j}\right)_{m \times n^{\prime}}$ according to the cost and benefit criteria.

Step 2: To determine the reference criterion $c_{r}$ and calculate the relative weight $w_{j r}$ of criterion $c_{j}(j=1,2, \ldots, n)$, i.e.,

$$
w_{j r}=w_{c_{j}} / w_{r}
$$

where $w_{r}=\max \left\{w_{c_{j}} \mid j=1,2, \ldots, n\right\}$.

Step 3: To calculate the dominance degree, $\Phi_{j}\left(p_{i}, p_{k}\right)$, of alternative $p_{i},(i=1,2, \ldots, m)$ over the remaining alternatives $p_{k}(k=1,2, \ldots, m)$ concerning criterion $c_{j}(j=1,2, \ldots, n)$, i.e.,

$$
\Phi_{j}\left(p_{i}, p_{k}\right)=\left\{\begin{array}{l}
\sqrt{w_{j r} /\left(\sum_{j=1}^{n} w_{j r}\right) d\left(g_{i j}, g_{k j}\right)}, \mathbb{F}\left(g_{i j}\right)-\mathbb{F}\left(g_{k j}\right) \geq 0 \\
-\frac{1}{\theta} \sqrt{\left(\sum_{j=1}^{n} w_{j r}\right) / w_{j r} d\left(g_{i j}, g_{k j}\right)}, \mathbb{F}\left(g_{i j}\right)-\mathbb{F}\left(g_{k j}\right)<0
\end{array}\right.
$$

where $\theta$ is the attenuation factor of the losses, $\theta>0 . d\left(g_{i j}, g_{k j}\right)$ denotes the distance between two fuzzy numbers $g_{i j}$ and $g_{k j}$ and $\mathbb{F}(*)$ is a defuzzification function [18].

Step 4: To calculate the dominance degree, $\delta\left(p_{i}, p_{k}\right)$, of alternative $p_{i},(i=1,2, \ldots, m)$ over the remaining alternatives $p_{k}(k=1,2, \ldots, m)$, i.e.,

$$
\delta\left(p_{i}, p_{k}\right)=\sum_{j=1}^{n} \Phi_{j}\left(p_{i}, p_{k}\right)
$$

Step 5: To calculate the overall dominance degree, $\eta\left(p_{i}\right)$, of alternative $p_{i},(i=1,2, \ldots, m)$, i.e.,

$$
\eta\left(p_{i}\right)=\frac{\sum_{k=1}^{m} \delta\left(p_{i}, p_{k}\right)-\min _{i}\left\{\sum_{k=1}^{m} \delta\left(p_{i}, p_{k}\right)\right\}}{\max _{i}\left\{\sum_{k=1}^{m} \delta\left(p_{i}, p_{k}\right)\right\}-\min _{i}\left\{\sum_{k=1}^{m} \delta\left(p_{i}, p_{k}\right)\right\}}
$$

Step 6: According to the overall dominance degrees of each alternative, the corresponding ranking can be determined such that the bigger $\eta\left(p_{i}\right)$, the better alternative $p_{i}$.

\subsection{Related Works}

In order to show the importance of GEDM in the real world, this subsection reviews several important studies in the literature that are related to our research [1,4-6,40].

These studies have approached GEDM problems from different aspects. For example, Wang et al. [40] proposed a group emergency decision method based on prospect theory by using interval values. $\mathrm{Xu}$ et al. [4] proposed a consensus model for multi-criteria large group emergency decision making considering non-cooperative behaviors and minority opinions, wherein numerical 
value is employed to represent experts' assessments. Ju et al. [6] presented a model to evaluate emergency response capacity by using 2-tuple fuzzy linguistic information. $\mathrm{Xu}$ et al. [5] proposed a conflict-eliminating approach for GEDM problem. Levy and Taji [1] utilized a group analytic network process to construct a group decision support system to support hazard planning and emergency management under incomplete information.

So far, there is not any proposal in previous GEDM approaches $[1,4,5,11,40]$ that considers the non-homogeneous information together with the experts' hesitation due to uncertain information. In addition, those GEDM approaches $[1,4,5,11]$ dealing with the consensus process; just make use of it with strict expression domains or high time cost. However, time is extremely valuable in EDM process, which means life and opportunity. Furthermore, experts' psychological behavior is neglected in current GEDM approaches $[1,4,5]$ that plays an important role in the GEDM process under risk and uncertainty.

As pointed out in Introduction, our proposed method aims to overcome such limitations and shows the relevance of this research.

\section{Managing Non-Homogeneous Information and Experts' Psychological Behavior in GEDM}

This section introduces a new GEDM method to overcome the limitations pointed out in the Introduction regarding the current GEDM methods. This proposal is able: (i) to manage non-homogeneous information, including hesitant information (ii) to achieve consensus with low time cost, (iii) to take into account the experts' psychological behavior in the GEDM process.

Our proposal extends the general scheme of a GEDM process shown in Figure 1 by adding two new phases to deal with non-homogeneous information and calculate the criteria weights, and modifying another two phases (CRP and selection process), they are highlighted in Figure 2 by using dashed lines.

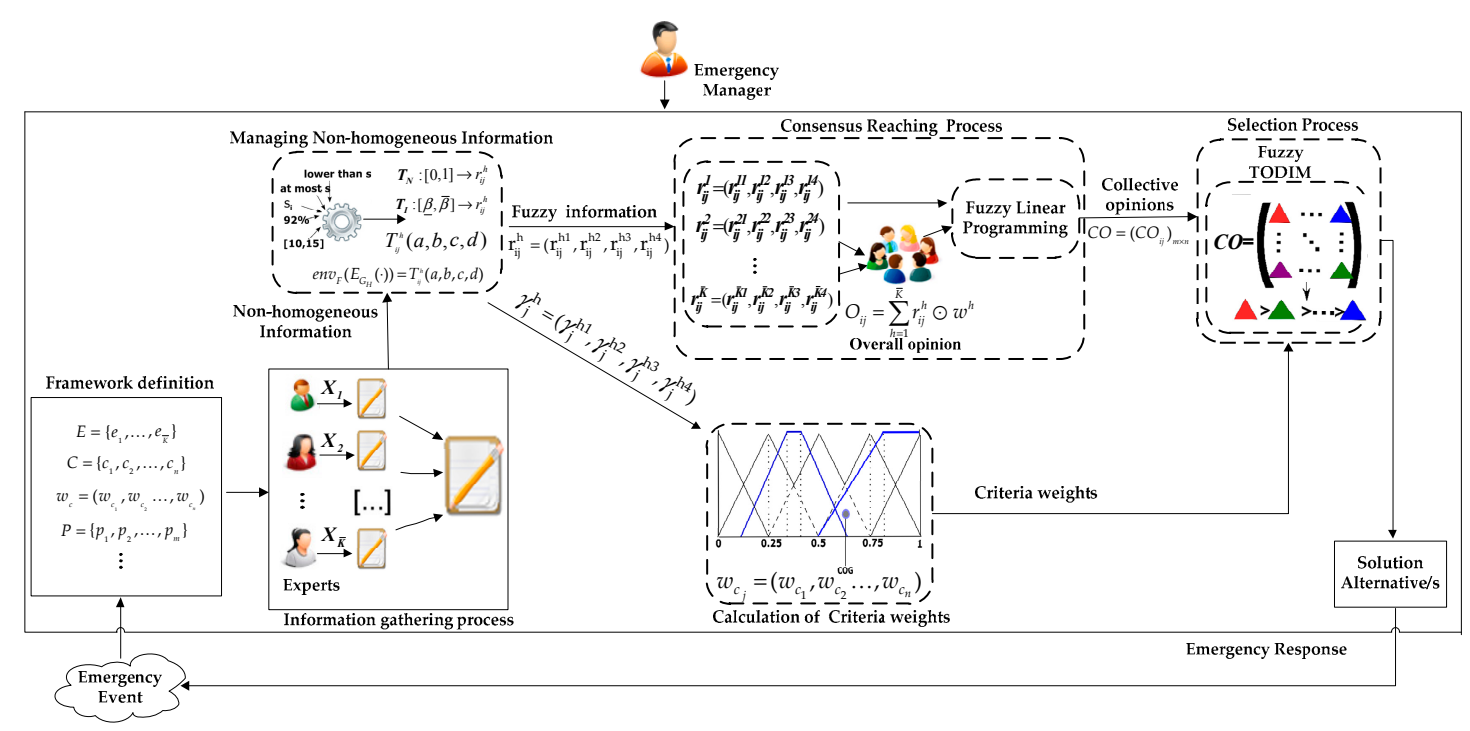

Figure 2. Scheme of proposed GEDM method.

It consists of six main phases:

1. Definition framework. The main features, terminology and expression domains utilized in the proposed GEDM problem are defined.

2. Information gathering process. Opinions or assessments over different alternatives concerning different criteria and importance of criteria provided by experts using multiple types of information are gathered. 
3. Managing non-homogeneous information. The non-homogeneous information gathered is unified into a fuzzy domain to deal with the decision computations.

4. Consensus reaching process. A fuzzy linear programming-based consensus model [34] is utilized to deal with fuzzy information and achieve an agreement among all the experts involved in the GEDM problem.

5. Calculation of criteria weights. Criteria weights are calculated by using experts' opinions.

6. Selection process-fuzzy TODIM method. Fuzzy TODIM method is applied to manage experts' psychological behavior in GEDM processes and obtain the ranking of alternatives.

According to the ranking of alternatives, the EM can select the best or more suitable alternative to cope with the EE. These phases are further detailed in the following subsections.

\subsection{Definition Framework}

The framework for GEDM problem is established by defining its main features and terminology.

- $\quad P=\left\{p_{1}, p_{2}, \ldots, p_{m}\right\}$ : the set of emergency alternatives, where $p_{i}$ is the $i$-th emergency alternative, $i=1,2, \ldots, m$.

- $C=\left\{c_{1}, c_{2}, \ldots, c_{n}\right\}$ : the set of criteria/attributes, where $c_{j}$ denotes the $j$-th criterion/attribute, $j=1,2, \ldots, n$.

- $\quad w_{c}=\left(w_{c_{1}}, w_{\mathcal{c}_{2}} \ldots, w_{\mathcal{c}_{n}}\right)$ : the weighting vector for the criteria, where $w_{\mathcal{c}_{j}}$ denotes the criterion weight of the $j$-th criterion/attribute, satisfying $\sum_{j=1}^{n} w_{c_{j}}=1, w_{c_{j}} \in[0,1] j=1,2, \ldots, n$.

- $E=\left\{e_{1}, \ldots, e_{\bar{K}}\right\}$ : the set of experts, where $e_{h}$ denotes the $h$-th expert, $h=1,2, \ldots, \bar{K}$.

- $X_{h}=\left(x_{i j}^{h}\right)_{m \times n}$ : the information matrix provided by the $h$-th expert, where $x_{i j}^{h}$ represents the assessments/opinions provided by the $h$-th expert over the $i$-th alternative concerning the $j$-th criterion, $h=1,2, \ldots, \bar{K}, i=1,2, \ldots, m, j=1,2, \ldots, n$ (see Remark 1 ).

- $\quad w_{h}=\left(w_{1}^{h}, w_{2}^{h} \ldots, w_{n}^{h}\right)$ : the assessment vector of criteria importance provided by the expert $e_{h}$, where $w_{j}^{h}$ represents the importance provided by the $h$-th expert on the importance of criterion $c_{j}$, $h=1,2, \ldots, \bar{K}, j=1,2, \ldots, n$ (see Remark 2).

- $\quad r_{i j}^{h}$ : denotes the experts' assessments, $x_{i j}^{h}$, unified in a fuzzy domain, $h=1,2, \ldots, \bar{K}, i=1,2, \ldots, m$, $j=1,2, \ldots, n$.

- $\gamma_{j}^{h}$ : denotes the experts' opinions regarding the criteria importance, $w_{j}^{h}$, unified in a fuzzy domain, $h=1,2, \ldots, \bar{K}, j=1,2, \ldots, n$.

Remark 1. In our method, experts can provide their opinions/assessments by utilizing multiple expression domains (numerical values $(N)$, interval values $(I)$, linguistic terms $(S)$ and comparative linguistic expressions $\left.\left(S_{l l}\right)\right)$ according to their background, degree of knowledge, hesitancy and criteria nature.

$$
x_{i j}^{h} \in\left\{\begin{array}{l}
N \in R \\
I \in\left[\xi^{L}, \xi^{U}\right] \\
S=\left\{s_{0}, s_{1}, \ldots, s_{g}\right\} \\
S_{l l}
\end{array}\right.
$$

Remark 2. In GEDM problems, the criteria need to be weighted. However, due to the complexity of EEs, it is not easy to collect the related information about the criteria, especially at the early stage of EE. In such situation, a possible way is to calculate the criteria weights from experts' knowledge and experience. In this proposal, experts can express their opinions about the criteria importance by utilizing either $S_{l l}$ or $S$, because $S_{l l}$ and $S$ are 
more flexible and similar to the natural language utilized by human beings in real-world EE situations, and they are suitable for GEDM problems defined in uncertain contexts.

$$
w_{j}^{h} \in\left\{\begin{array}{l}
S=\left\{s_{0}, s_{1}, \ldots, s_{g}\right\} \\
S_{l l}
\end{array}\right.
$$

\subsection{Information Gathering Process}

Once the framework of GEDM problem is defined, experts can provide their judgments over the emergency alternatives $p_{i}$ concerning each criterion $c_{j}$ and the importance over different criteria (see Tables 1 and 2) by using the expression domains defined previously.

Table 1. Assessments over alternative $p_{i}$ concerning criterion $c_{j}$.

\begin{tabular}{cc}
\hline Experts & Assessments \\
\hline$e_{1}$ & $\left\{x_{i j}^{1}, \ldots, x_{m n}^{1}\right\}$ \\
$e_{2}$ & $\left\{x_{i j}^{2}, \ldots, x_{m n}^{2}\right\}$ \\
$\ldots \ldots$ & $\ldots \ldots$ \\
$e_{\bar{K}}$ & $\left\{x_{i j}^{\bar{K}}, \ldots, x_{m n}^{\bar{K}}\right\}$ \\
\hline
\end{tabular}

Table 2. Importance over criteria $c_{j}$.

\begin{tabular}{cc}
\hline Experts & Assessments \\
\hline$e_{1}$ & $\left\{w_{1}^{1}, \ldots, w_{n}^{1}\right\}$ \\
$e_{2}$ & $\left\{w_{1}^{2}, \ldots, w_{n}^{2}\right\}$ \\
$\ldots \ldots$ & $\ldots \ldots$ \\
$e_{\bar{K}}$ & $\left\{w_{1}^{\bar{K}}, \ldots, w_{n}^{\bar{K}}\right\}$ \\
\hline
\end{tabular}

For example, the information on alternatives with respect to criteria provided by expert $e_{1}$ can be expressed as:

$$
X_{1}=\begin{gathered}
c_{1} \\
p_{2} \\
\vdots \\
p_{m}
\end{gathered}\left[\begin{array}{cccc}
x_{11}^{1} & x_{2} & \ldots & c_{n} \\
x_{21}^{1} & x_{22}^{1} & \ldots & x_{1 n}^{1} \\
\vdots & \vdots & \cdots & x_{2 n}^{1} \\
x_{m 1}^{1} & x_{m 2}^{1} & \cdots & x_{m n}^{1}
\end{array}\right]
$$

where $x_{i j}^{1} \in\left\{\begin{array}{l}N \in R \\ I \in\left[\xi^{L}, \xi^{U}\right] \\ S=\left\{s_{0}, s_{1}, \ldots, s_{g}\right\} \\ S_{l l}\end{array}, i=1,2, \ldots, m, j=1,2, \ldots, n\right.$.

The information on the importance of criterion $c_{j}$ provided by expert $e_{1}$ can be expressed as:

$$
w_{1}=\left[\begin{array}{rrrr}
c_{1} & c_{2} & \cdots & c_{n} \\
w_{1}^{1} & w_{2}^{1} & \cdots & w_{n}^{1}
\end{array}\right]
$$

where $w_{j}^{1} \in\left\{\begin{array}{l}S=\left\{s_{0}, s_{1}, \ldots, s_{g}\right\} \\ S_{l l}\end{array}, j=1,2, \ldots, n\right.$. 


\subsection{Managing Non-Homogeneous Information}

As it was stated in Section 2.1, our proposal deals with non-homogeneous information including hesitant information. Therefore, the expression domains used by experts to provide their assessments in this proposal are the following ones:

- $\quad$ Numerical value. Assessments represented as numerical values $N$ belonging to a specific numerical scale $R$, i.e., $N \in R$.

- Interval value. Assessments represented as interval values $I$, belonging to a specific domain $\left[\xi^{L}, \xi^{U}\right]$, i.e., $I \in\left[\xi^{L}, \xi^{U}\right]$.

- Linguistic terms. Assessments represented as linguistic terms $s_{k} \in S=\left\{s_{0}, s_{1}, \ldots, s_{g}\right\}$, $k \in\{0, \ldots, g\}$, with granularity $g+1$.

- Comparative linguistic expressions. Assessments represented as comparative linguistic expressions $S_{l l}$ generated by a context-free grammar $G_{H}[29,30]$.

In order to make computations with non-homogeneous information elicited by experts, it is necessary to conduct the different types of information into a unique expression domain. Most approaches unify the non-homogeneous information into linguistic information [23,24]. Nevertheless, in order to keep the uncertainty provided by experts involved in a GEDM problem, we unify the information into a fuzzy domain $r_{i j}^{h}$, by introducing some transformation functions (see Figure 3).

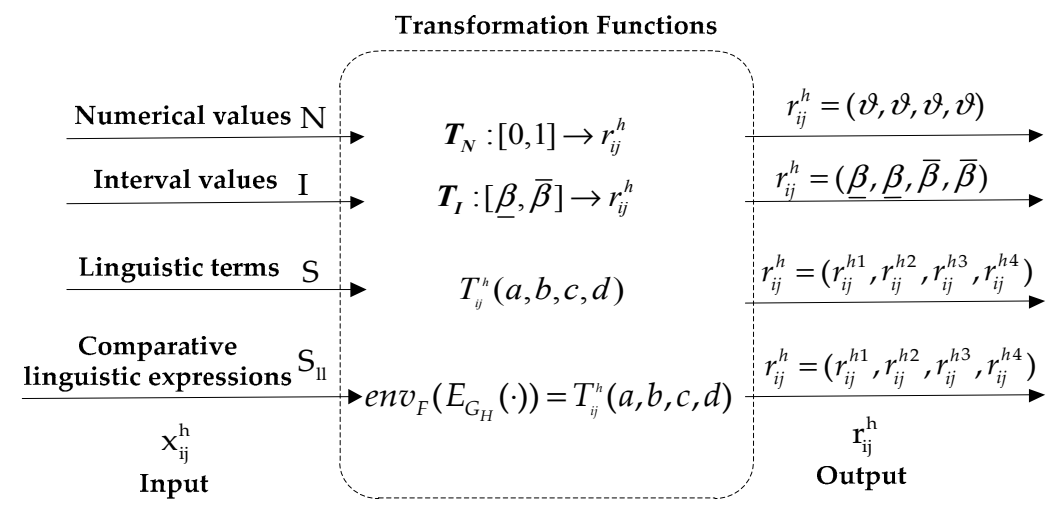

Figure 3. Unification process for non-homogeneous information.

The following transformation functions are defined to unify the information into a fuzzy domain.

1. For numerical values $N$, they are first normalized into the interval $[0,1]$ and then a transformation function $T_{N}$ is utilized to transform them into trapezoidal fuzzy numbers. Let $R$ be the domain of the numerical values, $N_{i j}^{h}$ be the numerical value provided by the $h$-th expert over the $i$-th alternative concerning the $j$-th criterion, $N_{i j}^{h}$ is normalized into the interval $[0,1]$, as follows:

$$
\vartheta=\frac{N_{i j}^{h}}{N^{*}}
$$

where $\vartheta \in[0,1], N^{*}=\max _{h=1,2, \ldots, \bar{K}}\left\{N_{i j}^{h}\right\}, i=1,2, \ldots, m, j=1,2, \ldots, n$.

Definition 3. A numerical value is transformed into a trapezoidal fuzzy number by utilizing a transformation function $T_{N}$ :

$$
T_{N}:[0,1] \rightarrow r_{i j}^{h}
$$




$$
T_{N}(\vartheta)=r_{i j}^{h}=(\vartheta, \vartheta, \vartheta, \vartheta)
$$

2. The interval values $I$ are first normalized into $[0,1]$ and then a transformation function $T_{I}$ is utilized to transform them into trapezoidal fuzzy numbers. Let $\left[\xi^{L}, \xi^{U}\right]$ be the domain of the interval values, let $\left[d^{L}, d^{U}\right]_{i j}^{h}$ be the interval values provided by the $h$-th expert over the $i$-th alternative concerning the $j$-th criterion, where $\left[d^{L}, d^{U}\right]_{i j}^{h} \in\left[\xi^{L}, \xi^{U}\right]$. The interval values $\left[d^{L}, d^{U}\right]_{i j}^{h}$ are normalized into $[\beta, \bar{\beta}]$ as follows:

$$
\underline{\beta}=\frac{d^{L}-\xi^{L}}{\xi^{U}-\xi^{L}} \text { and } \bar{\beta}=\frac{d^{U}-\xi^{L}}{\xi^{U}-\xi^{L}}
$$

The transformation function $T_{I}$ is defined as follows.

Definition 4. An interval value is transformed into a trapezoidal fuzzy number by utilizing a transformation function $T_{I}$ :

$$
\begin{gathered}
T_{I}:[\underline{\beta}, \bar{\beta}] \rightarrow r_{i j}^{h} \\
T_{I}(\underline{\beta}, \bar{\beta})=r_{i j}^{h}=(\underline{\beta}, \underline{\beta}, \bar{\beta}, \bar{\beta})
\end{gathered}
$$

where $\underline{\beta}, \bar{\beta} \in[0,1]$ and $\underline{\beta} \leq \bar{\beta}$.

3. The linguistic terms $s_{k} \in S=\left\{s_{0}, s_{1}, \ldots, s_{g}\right\}$, are represented by trapezoidal fuzzy numbers. Therefore, the expert $e_{h}$ provides his/her opinions over the $i$-th alternative concerning the $j$-th criterion as a linguistic term $s_{k}$ that is represented by a trapezoidal fuzzy number $r_{i j}^{h}=\left(r_{i j}^{h 1}, r_{i j}^{h 2}, r_{i j}^{h 3}, r_{i j}^{h 4}\right)$.

4. The comparative linguistic expressions, $x_{i j}^{h} \in S_{l l}$, are transformed into HFLTS by $E_{G_{H}}(\cdot)$ and its fuzzy envelop $e n v_{F}(\cdot)$ obtained by [41],

$$
\operatorname{env}_{F}\left(E_{G_{H}}\left(x_{i j}^{h}\right)\right)=T_{i j}^{h}(a, b, c, d)=r_{i j}^{h}
$$

$E_{G_{H}}$ is a function that transforms the linguistic expressions obtained by using $G_{H}$, into HFLTS [30]. $T_{i j}^{h}(a, b, c, d)$ is a trapezoidal fuzzy membership function corresponding to the trapezoidal fuzzy number $r_{i j}^{h}=\left(r_{i j}^{h 1}, r_{i j}^{h 2}, r_{i j}^{h 3}, r_{i j}^{h 4}\right)$.

\subsection{Consensus Reaching Process}

As stated in Section 2.2, a fuzzy linear programming-based consensus model [34] is used in our proposal to achieve an agreement among all the experts involved in the problem. This model is able to deal with fuzzy information and update experts' opinions automatically without a supervised feedback mechanism [33], which is adequate for GEDM problems defined in fuzzy environment (see Figure 4). 


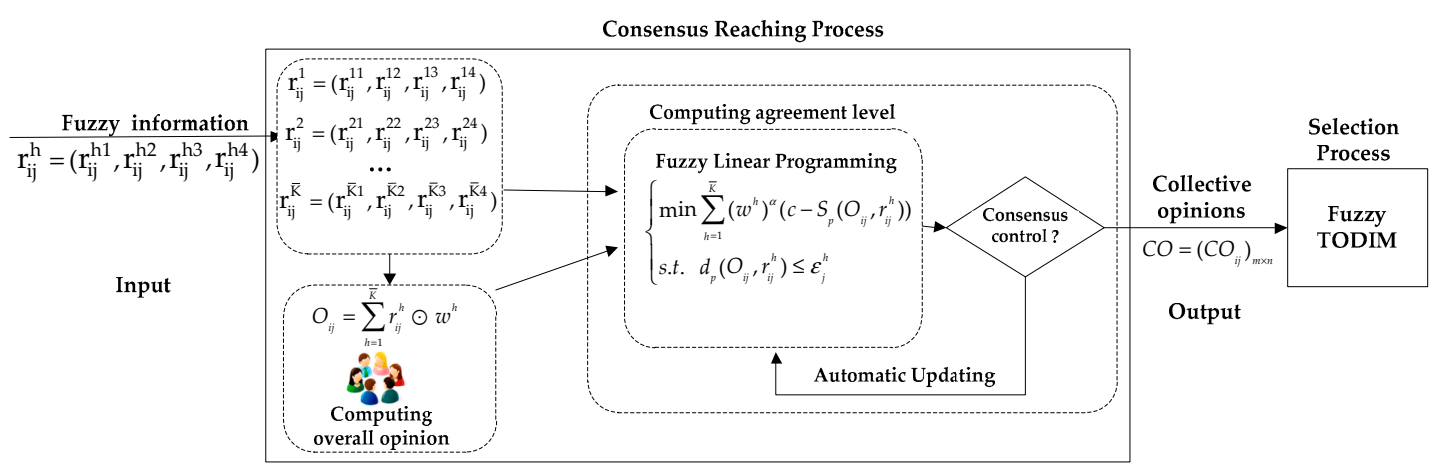

Figure 4. The process of fuzzy linear programming-based consensus model.

The fuzzy linear programming-based consensus model is given by,

$$
\left\{\begin{array}{l}
\min \sum_{h=1}^{\bar{K}}\left(w^{h}\right)^{\alpha}\left(c-S_{p}\left(O_{i j}, r_{i j}^{h}\right)\right) \\
\text { s.t. } d_{p}\left(O_{i j}, r_{i j}^{h}\right) \leq \varepsilon_{j}^{h}, h=1,2, \ldots, \bar{K} ; j=1,2, \ldots, n, i=1,2, \ldots, m .
\end{array}\right.
$$

According to Figure 4, the input information is represented in a fuzzy domain, which is obtained from the previous phase. It consists of three steps that are further detailed as follows:

1. Computing overall opinion. As introduced in Section 2.2, before applying fuzzy linear programming model, the overall opinions, $O_{i j}$, are obtained by aggregating the individual expert opinions, $r_{i j}^{h}$. Let $O_{i j}$ be the overall opinion over the $i$-th alternative concerning the $j$-th criterion. It can be obtained as follows:

$$
O_{i j}=\sum_{h=1}^{\bar{K}} r_{i j}^{h} \odot w^{h}, h=1,2, \ldots, \bar{K}, j=1,2, \ldots, n, i=1,2, \ldots, m .
$$

where $\odot$ is an aggregation operator. For example, suppose that $r_{12}^{1}=(0.17,0.34,0.5,0.67)$, $r_{12}^{2}=(0,0.17,0.34,0.5)$ and $\left(w^{1}, w^{2}\right)=(0.6,0.4)$, then $O_{12}$ could be computed by a weighted average operator:

$$
\begin{aligned}
O_{12} & =0.6 \odot(0.17,0.34,0.5,0.67)+0.4 \odot(0,0.17,0.34,0.5) \\
& =(0.102,0.272,0.436,0.602)
\end{aligned}
$$

2. Computing agreement level. In this step, there are two processes:

(i) Computing the distance and similarity. The distance, $d_{p}\left(O_{i j}, r_{i j}^{h}\right)$, between the overall opinion, $O_{i j}$, and the individual opinion, $r_{i j}^{h}$ and its similarity, $S_{p}\left(O_{i j}, r_{i j}^{h}\right)$, can be computed according to Equations (1) and (2) respectively.

(ii) Determining the threshold values. The threshold value, $\varepsilon_{j}^{h}$, is an important factor in the fuzzy linear programming model, which means the maximum change that the expert $e_{h}$ can make concerning the $j$-th criterion. There are different ways to determine the threshold value $\varepsilon_{j}^{h}[34,35]$. In this paper, $\varepsilon_{j}^{h}$ will be calculated by the $h$-th experts' familiarity degree concerning the $j$-th criterion using a linguistic term set $S=\left\{s_{0}, s_{1}, \ldots, s_{g}\right\}$, because the linguistic terms are flexible and able to deal with uncertain and vague information. The more familiar the expert is with the criterion, the less change he/she will make. Therefore, a negative operator is applied to the familiarity degree to obtain the threshold, which is defined as follows: 
Definition 5. Let $S=\left\{s_{0}, s_{1}, \ldots, s_{g}\right\}$ be a linguistic term set, a negative operator:

$$
\operatorname{Neg}\left(s_{k}\right)=\widetilde{s}_{q} \text {, such that } q=g-k, k=\{0, \ldots, g\} \text {. }
$$

where $g+1$ is the cardinality of $S$.

Thus, the $\varepsilon_{j}^{h}$ can be computed by using the center of gravity (COG) method [42], i.e., $\varepsilon_{j}^{h}=\operatorname{COG}\left(\widetilde{s}_{q}\right)$ (see Equation (18)).

3. Control consensus. When all constraints meet the conditions in Equation (14), it means that the consensus has been reached, and the final overall opinion, $O_{i j}$, is the aggregated collective opinion denoted as $C O=\left(\mathrm{CO}_{i j}\right)_{m \times n}$ Which will be used as input in the selection process.

\subsection{Calculation of Criteria Weights}

In this phase, the weights of criteria, $w_{c_{j}}$, are calculated by utilizing the experts' assessments provided over the criteria importance which were unified into a fuzzy domain. Figure 5 shows the process of computing criteria weights.

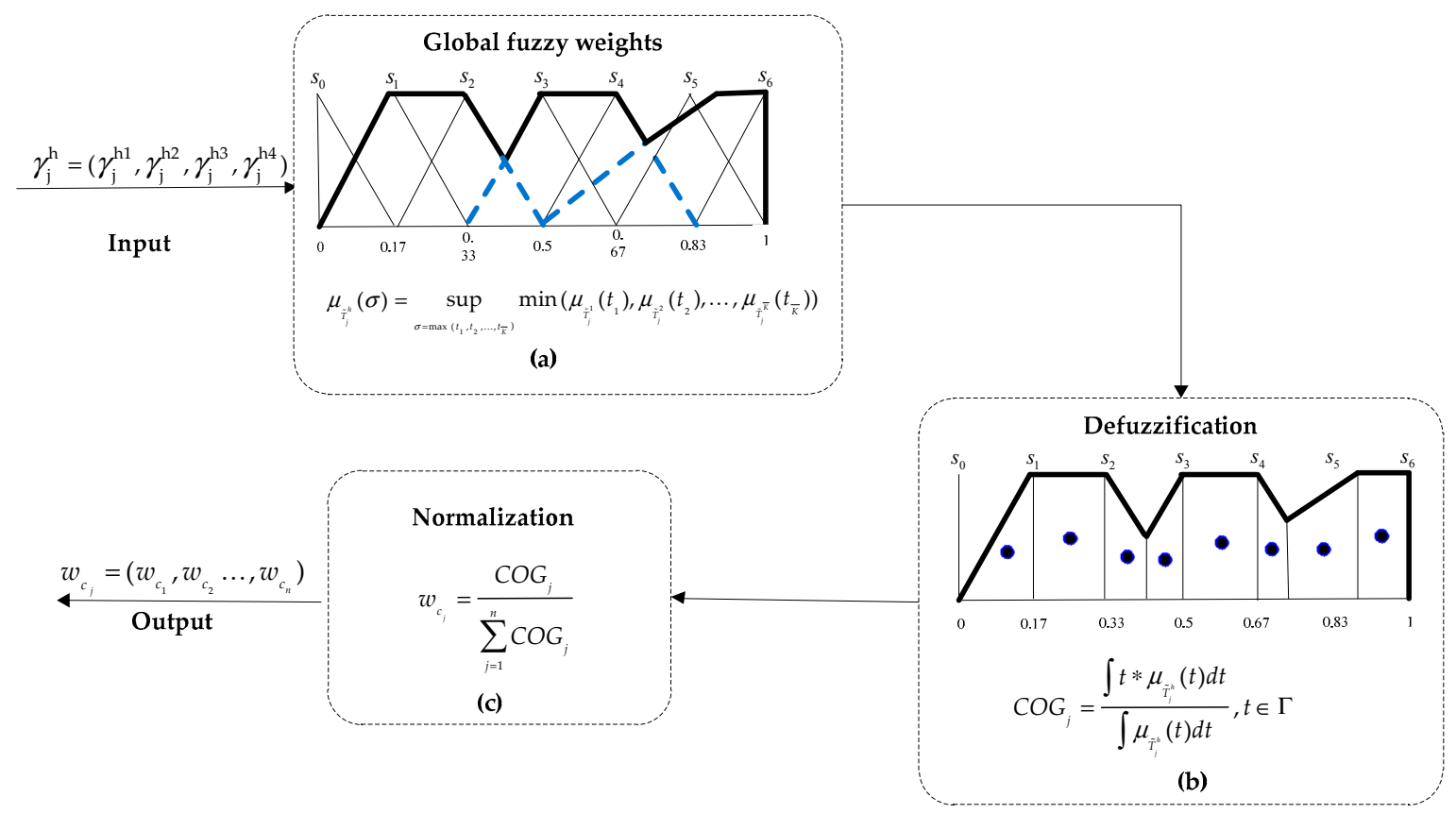

Figure 5. Computing criteria weights.

Three steps are comprised:

1. Global fuzzy weights. The fuzzy weights obtained for the criterion $c_{j}$ are aggregated by using a max-min composition [43,44]:

$$
\mu_{\widetilde{T}_{j}^{h}}(\sigma)=\sup _{\sigma=\max \left(t_{1}, t_{2}, \ldots, t_{\bar{K}}\right)} \min \left(\mu_{\widetilde{T}_{j}^{1}}\left(t_{1}\right), \mu_{\widetilde{T}_{j}^{2}}\left(t_{2}\right), \ldots, \mu_{\widetilde{T}_{j}^{\bar{K}}}\left(t_{\bar{K}}\right)\right), t_{h} \in \Gamma, h \in\{1,2, \ldots, \bar{K}\}
$$

where $\widetilde{T}_{j}^{h}$ is the fuzzy membership function of $w_{j}^{h}, j=1,2, \ldots, n$, and $\Gamma$ is the universe of discourse. 
Suppose that three experts provide their opinions $w_{1}^{1}, w_{1}^{2}$ and $w_{1}^{3}$ concerning the criterion $c_{1}$, the corresponding fuzzy membership functions are $\widetilde{T}_{1}^{1}, \widetilde{T}_{1}^{2}$ and $\widetilde{T}_{1}^{3}$ respectively. According to Equation (17), $\mu_{\widetilde{T}_{j}^{h}}(\sigma)$ is the area under the bold black line shown in Figure $5 \mathrm{a}$.

2. Defuzzification. The COG method [42] is utilized to calculate the weighting value of the global fuzzy weights:

$$
C O G_{j}=\frac{\int t * \mu_{\widetilde{T}_{j}^{h}}(t) d t}{\int \mu_{\widetilde{T}_{j}^{h}}(t) d t}, t \in \Gamma
$$

where $\Gamma$ is the universe of discourse.

For criterion $c_{1}$, Equation (18) means that the center of gravity for each small trapezoid (see Figure $5 b$ ) is computed and the $\mathrm{COG}_{1}$ can be obtained by the arithmetic mean of the sum of center of gravity of all small trapezoids.

3. Normalization. When $C O G_{j}$ of all criteria are obtained, the criteria weights $w_{c_{j}}$ are calculated by using the following equation:

$$
w_{c_{j}}=\frac{C O G_{j}}{\sum_{j=1}^{n} C O G_{j}}
$$

where $\sum_{j=1}^{n} w_{c_{j}}=1, w_{c_{j}} \in[0,1] j=1,2, \ldots, n$.

\subsection{Selection Process-Fuzzy TODIM Method}

As it was pointed out in Introduction, the experts' psychological behavior are neglected in current GEDM approaches. However, our proposal takes into account experts' psychological behavior by means of fuzzy TODIM based on prospect theory dealing with the problem defined in a fuzzy environment.

Once the criteria weights $w_{c_{j}}$ and the aggregated collective opinions $C O=\left(\mathrm{CO}_{i j}\right)_{m \times n}$ are obtained, the fuzzy TODIM method is applied to obtain a ranking of alternatives and select the best one. To do so, the fuzzy TODIM method introduced in Section 2.3 is used. The step 1 is not necessary to do it, because the collective opinion matrix $\mathrm{CO}=\left(\mathrm{CO}_{i j}\right)_{m \times n^{\prime}}$ is already normalized and the step 3 has been modified to adapted it to GEDM problem as it is shown below:

Step 3: To calculate the dominance degree, $\Phi_{j}\left(p_{i}, p_{k}\right)$, of alternative $p_{i}(i=1,2, \ldots, m)$ over the remaining alternatives $p_{k}(k=1,2, \ldots, m)$ concerning criterion $c_{j}(j=1,2, \ldots, n)$, i.e.,

$$
\Phi_{j}\left(p_{i}, p_{k}\right)=\left\{\begin{array}{l}
\sqrt{d\left(C O_{i j}, C O_{k j}\right) w_{j r} /\left(\sum_{j=1}^{n} w_{j r}\right)}, \widetilde{m}\left(C O_{i j}\right)-\widetilde{m}\left(C O_{k j}\right) \geq 0 \\
-\frac{1}{\theta} \sqrt{d\left(C O_{i j}, C O_{k j}\right)\left(\sum_{j=1}^{n} w_{j r}\right) / w_{j r}}, \widetilde{m}\left(C O_{i j}\right)-\widetilde{m}\left(C O_{k j}\right)<0
\end{array}\right.
$$

$C O_{i j}$ denotes the trapezoidal fuzzy number $C O_{i j}=\left(C_{i j}^{1}, C O_{i j}^{2}, C O_{i j}^{3}, C O_{i j}^{4}\right)$ that represents the information about the $i$-th alternative concerning the $j$-th criterion. $\widetilde{m}\left(C O_{i j}\right)$ and $\widetilde{m}\left(C O_{k j}\right)$ denotes the defuzzified value of the fuzzy number $C O_{i j}$ and $C O_{k j}$, respectively, where $\widetilde{m}\left(\mathrm{CO}_{i j}\right)=\frac{\mathrm{CO}_{i j}^{1}+2 \mathrm{CO}_{i j}^{2}+2 \mathrm{CO}_{i j}^{3}+\mathrm{CO}_{i j}^{4}}{6}$ [42]. $d\left(\mathrm{CO}_{i j}, \mathrm{CO}_{k j}\right)$ denotes the gains or losses of the alternative $p_{i}$ over $p_{k}$ concerning the criterion $c_{j}$, where $d\left(\mathrm{CO}_{i j}, C O_{k j}\right)=\sqrt{\sum_{\ell=1}^{4}\left(\mathrm{CO}_{i j}^{\ell}-\mathrm{CO}_{k j}^{\ell}\right)^{2}}$ [45].

For benefit criteria, $d\left(C O_{i j}, C O_{k j}\right)$ denotes the gains with $\widetilde{m}\left(C O_{i j}\right)-\widetilde{m}\left(C O_{k j}\right) \geq 0$ or losses with $\widetilde{m}\left(C O_{i j}\right)-\widetilde{m}\left(C O_{k j}\right)<0$, respectively. $\Phi_{j}\left(p_{i}, p_{k}\right)$ can be expressed as:

$$
\Phi_{j}\left(p_{i}, p_{k}\right)=\left\{\begin{array}{l}
\sqrt{d\left(C O_{i j}, C O_{k j}\right) w_{j r} /\left(\sum_{j=1}^{n} w_{j r}\right)}, \widetilde{m}\left(C O_{i j}\right)-\widetilde{m}\left(C O_{k j}\right) \geq 0 \\
-\frac{1}{\theta} \sqrt{d\left(C O_{i j}, C O_{k j}\right)\left(\sum_{j=1}^{n} w_{j r}\right) / w_{j r}}, \widetilde{m}\left(C O_{i j}\right)-\widetilde{m}\left(C O_{k j}\right)<0
\end{array}\right.
$$


For cost criteria, $d\left(\mathrm{CO}_{i j}, \mathrm{CO}_{k j}\right)$ denotes the gains with $\widetilde{m}\left(\mathrm{CO}_{i j}\right)-\widetilde{m}\left(\mathrm{CO}_{k j}\right) \leq 0$ or losses with $\widetilde{m}\left(C O_{i j}\right)-\widetilde{m}\left(C O_{k j}\right)>0$, respectively, $\Phi_{j}\left(p_{i}, p_{k}\right)$ can be expressed as:

$$
\Phi_{j}\left(p_{i}, p_{k}\right)=\left\{\begin{array}{l}
\sqrt{d\left(C O_{i j}, C O_{k j}\right) w_{j r} /\left(\sum_{j=1}^{n} w_{j r}\right)}, \widetilde{m}\left(C O_{i j}\right)-\widetilde{m}\left(C O_{k j}\right) \leq 0 \\
-\frac{1}{\theta} \sqrt{d\left(C O_{i j}, C O_{k j}\right)\left(\sum_{j=1}^{n} w_{j r}\right) / w_{j r}}, \widetilde{m}\left(C O_{i j}\right)-\widetilde{m}\left(C O_{k j}\right)>0
\end{array}\right.
$$

Finally, the ranking of alternatives can be determined according to their overall dominance degree.

\section{Group Decision Support System for GEDM Based on GENESIS: Case Study}

EEs are always characterized by complexity, risk and uncertainty, and a delayed or wrong decision may result in extremely serious consequences. Thus, it is necessary to make a decision in short time, taking into account the opinions of multiple experts involved in the problem.

In order to deal properly with real-world GEDM problems and make timely and effective decisions, we have implemented a GDSS named GENESIS to support the proposed GEDM method. This section introduces the structure and components of GENESIS (see Figure 6); and shows a case study to illustrate the applicability and robustness of the proposed method by using GENESIS.

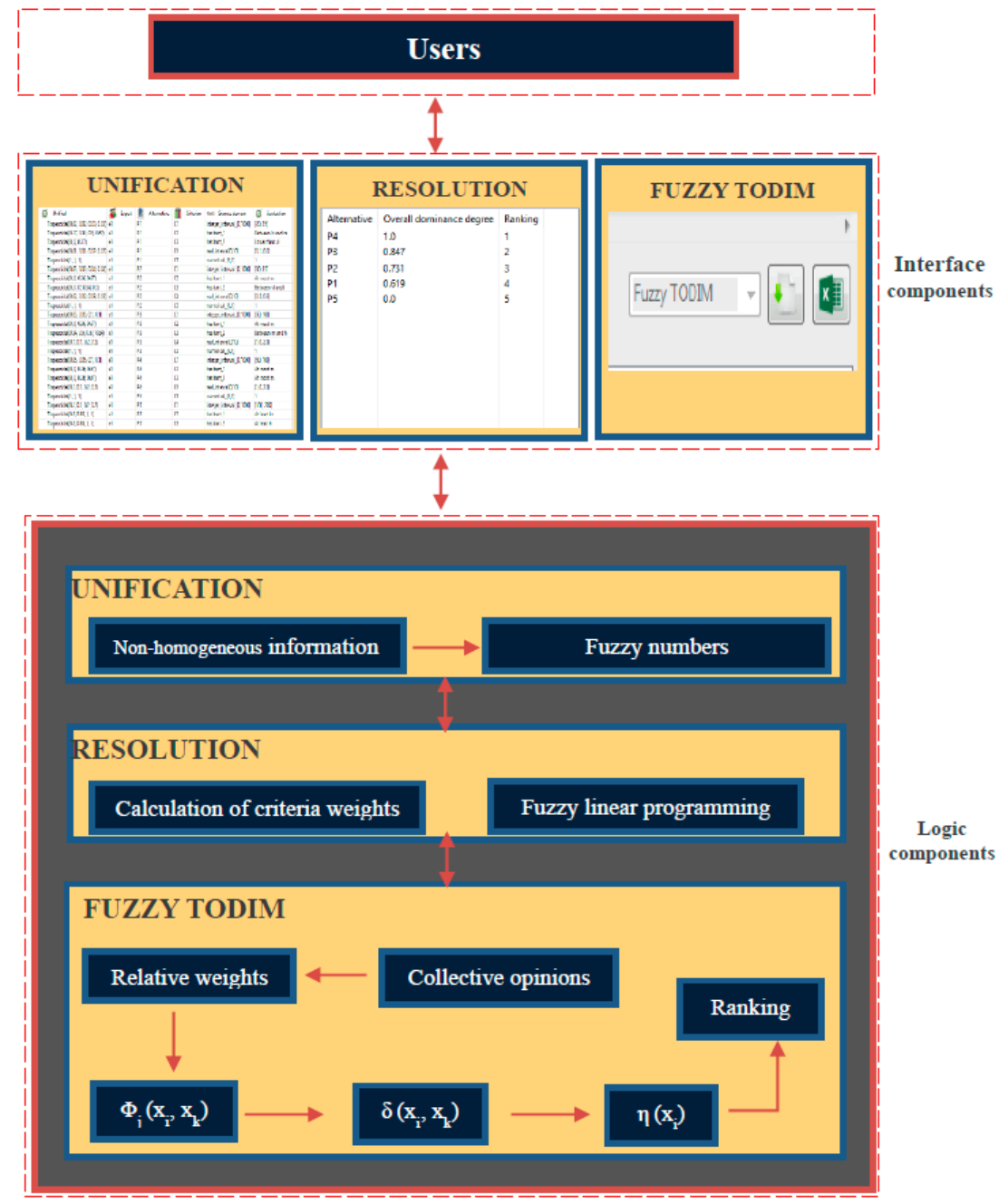

Figure 6. Structure of GENESIS. 


\subsection{GENESIS: (Group EmergeNcy dEcision SupportIng System)}

Since our proposal deals with non-homogeneous and fuzzy information, in order to facilitate the transformation of non-homogeneous information and the decision process of the proposed method in a simple and fast manner, GENESIS has been implemented to use different components and specific functions based on FLINTSTONES [19,20] developed by using Eclipse Rich Client Platform (Eclipse RCP), which is a component-based application [46], a platform that builds and deploys rich client applications.

GENESIS consists of six components (see Figure 6):

(1) Two components taken from FLINTSTONES are adapted to define different transformation functions to unify non-homogeneous information into a fuzzy domain and show its user interface respectively.

(2) Two new components are defined for the resolution processes and show their interface to compute the criteria weights and obtain the consensus opinion based on fuzzy linear programming-based consensus model.

(3) Two new components are introduced to carry out the steps defined in the fuzzy TODIM method such as the computation of the relative weights, dominance degree etc., and show its user interface.

\subsection{Case Study}

In order to demonstrate the applicability of the proposed GEDM method, this section presents an example adapted from a big explosion of Tianjin Port that occurred in the north of China (Background Information Source. http:/ / www.safehoo.com/Case/Case/Blow/201602/428723.shtml).

The blasts took place at a warehouse at the port that contained hazardous and flammable chemicals, including calcium carbide, sodium cyanide, potassium nitrate, ammonium nitrate and sodium nitrate, etc.

In this problem, we assume that six experts are invited to participate in the EDM process to support the EM to make the final decision. In order to solve this GEDM problem, we have used the proposed method by means of GENESIS.

\subsubsection{Framework Definition}

When the explosion occurred, the local government organized people located within two kilometers of the explosion area, evacuated them to safety areas and sent short messages to inform people in potentially dangerous areas to prepare for evacuation and keep distances from the dangerous area. Five emergency alternatives $\left\{p_{1}, p_{2}, \ldots, p_{5}\right\}$ were put forward taking into account five criteria $\left\{c_{1}, c_{2}, \ldots, c_{5}\right\}$, which are described in Tables 3 and 4 , respectively.

For the criteria importance, the linguistic term set is $S_{1}=$ \{absolutely low importance (ali), very low importance (vli), low importance (li), medium importance (mi), high importance (hi), very high importance (vhi), absolutely high importance (ahi)\}. (see Figure 7 "syntax for $S_{1}{ }^{\prime \prime}$ )

For criteria $C_{2}$ and $C_{3}$, the experts provide their opinions using linguistic term sets $S_{2}=$ \{none $(n)$, very low seriously (vls), low seriously (ls), medium ( $m$ ), high seriously (hs), very high seriously (vhs), absolutely seriously (as) $\}$ and $S_{3}=\{$ none $(n)$, very low $(v l)$, low $(l)$, medium $(m)$, high $(h)$, very high $(v h)$, absolutely high $(a h)\}$ (see Figure 7 "syntax for $C_{2}$ " and "syntax for $C_{3}$ "), respectively. 
Table 3. Description of alternatives.

\begin{tabular}{cl}
\hline Alternative & \multicolumn{1}{c}{ Description } \\
\hline Evacuate people $\left(p_{1}\right)$ & $\begin{array}{l}\text { Evacuate and inform people, and at same time, assign 9 fire squadrons } \\
\text { and } 35 \text { fire engines to deal with the emergency event. }\end{array}$ \\
\hline Increase help and report $\left(p_{2}\right)$ & $\begin{array}{l}\text { Increase to } 23 \text { fire squadrons, } 93 \text { fire engines and more than } 600 \text { fire } \\
\text { fighters for participating in dealing with the emergency event; at the } \\
\text { same time, the local government report the latest news to the masses } \\
\text { in order to avoid causing panic and riot. }\end{array}$ \\
\hline Rescue military $\left(p_{3}\right)$ & $\begin{array}{l}\text { Local government asks the Chinese professional emergency rescue } \\
\text { military for emergency rescue. More than 300 soldiers with } \\
\text { professional equipment join the rescue action. }\end{array}$ \\
\hline Joint rescue $\left(p_{4}\right)$ & $\begin{array}{l}\text { Fire squadrons and the military work together dealing with the } \\
\text { problems, at the same time, local government asks neighbor cities for } \\
\text { fire police to provide support. }\end{array}$ \\
\hline Block boundary of explosion areas $\left(p_{5}\right)$ & $\begin{array}{l}\text { Block the boundary of the explosion areas; let the material in the } \\
\text { explosion areas burn down. }\end{array}$ \\
\hline
\end{tabular}

Table 4. Description of criteria.

\begin{tabular}{ccl}
\hline Criteria & Expression Domain & \multicolumn{1}{c}{ Description } \\
\hline People affected $\left(C_{1}\right)$ & Interval values & $\begin{array}{l}\text { It means that alternative } p_{i} \text { can protect the number } \\
\text { of people from the effects caused by EE in [0,1000]. }\end{array}$ \\
\hline Negative effect on the environment $\left(C_{2}\right)$ & Linguistic & It is evaluated by experts on linguistic expressions. \\
\hline Social impacts $\left(C_{3}\right)$ & Linguistic & $\begin{array}{l}\text { It means the impacts on social development or } \\
\text { people's daily life etc. that are evaluated by experts } \\
\text { on linguistic expressions. }\end{array}$ \\
\hline Property loss $\left(C_{4}\right)$ & Interval values & $\begin{array}{l}\text { It means that the alternative } p_{i} \text { can protect the } \\
\text { direct and indirect property losses that are caused } \\
\text { by the EE in [0,10]. (in billion RMB). }\end{array}$ \\
\hline Cost of alternative $\left(C_{5}\right)$ & Numerical values & $\begin{array}{l}\text { The numerical values are } 0 \text { and } 1.0 \text { means that } \\
\text { expert } e_{h} \text { does not care about the cost; } 1 \text { means that } \\
\text { he/she cares about it. }\end{array}$ \\
\hline
\end{tabular}

Note: assume that above criteria are independent.

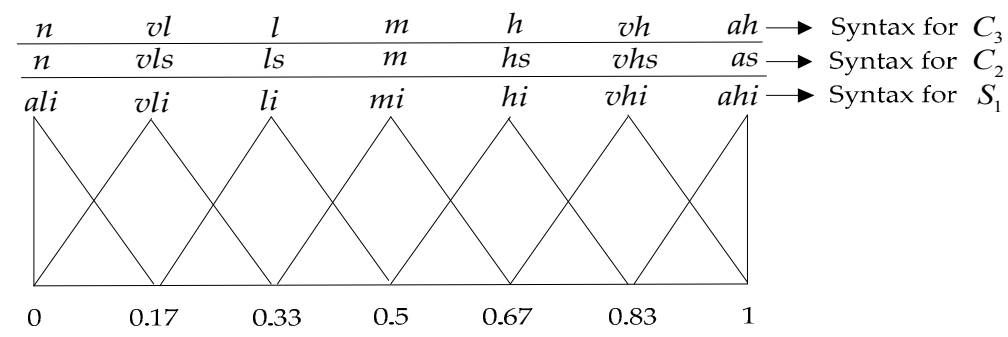

Figure 7. Linguistic term set for $S_{1}, C_{2}$ and $C_{3}$.

\subsubsection{Information Gathering Process}

The assessments provided by experts over the alternatives concerning criteria, and their opinions regarding the criteria importance and the familiarity degree for each criterion are shown in Tables 5-7 respectively. This phase is supported by GENESIS to facilitate the information gathering process (see Figure 8). 
Table 5. Assessments provided by all experts on different alternatives concerning each criterion.

\begin{tabular}{|c|c|c|c|c|c|c|}
\hline \multirow{2}{*}{ Expert } & \multirow{2}{*}{ Alternative } & \multicolumn{5}{|c|}{ Criteria } \\
\hline & & $C_{1}$ & $C_{2}$ & $C_{3}$ & $C_{4}$ & $C_{5}$ \\
\hline & & $\begin{array}{c}\text { Interval Values } \\
{[0,1000]}\end{array}$ & Linguistic & Linguistic & $\begin{array}{c}\text { Interval } \\
\text { Values }[0,10]\end{array}$ & $\begin{array}{l}\text { Numerical } \\
\text { Values }(0,1)\end{array}$ \\
\hline \multirow{5}{*}{$e_{1}$} & $P_{1}$ & {$[20,25]$} & ls & $l$ & {$[0.2,0.3]$} & 1 \\
\hline & $P_{2}$ & {$[30,35]$} & ls & $m$ & {$[0.2,0.35]$} & 1 \\
\hline & $P_{3}$ & {$[50,80]$} & $m$ & $h$ & {$[0.5,0.8]$} & 1 \\
\hline & $P_{4}$ & {$[100,150]$} & $h s$ & $b t m$ and $h$ & {$[1.0,2.0]$} & 1 \\
\hline & $P_{5}$ & {$[60,70]$} & vhs & $v h$ & {$[0.1,0.2]$} & 1 \\
\hline \multirow{5}{*}{$e_{2}$} & $P_{1}$ & {$[30,50]$} & vls & At most $v l$ & {$[0.25,0.4]$} & 1 \\
\hline & $P_{2}$ & {$[40,50]$} & vls & $v l$ & {$[0.3,0.5]$} & 1 \\
\hline & $P_{3}$ & {$[100,150]$} & ls & $m$ & {$[0.6,1.5]$} & 1 \\
\hline & $P_{4}$ & {$[150,250]$} & $m$ & $l$ & {$[2.0,2.5]$} & 1 \\
\hline & $P_{5}$ & {$[80,100]$} & hs & $v h$ & {$[0.1,0.25]$} & 1 \\
\hline \multirow{5}{*}{$e_{3}$} & $P_{1}$ & {$[20,30]$} & vls & $l$ & {$[0.1,0.15]$} & 1 \\
\hline & $P_{2}$ & {$[30,60]$} & ls & $l$ & {$[0.15,0.25]$} & 1 \\
\hline & $P_{3}$ & {$[60,100]$} & $b t l s$ and $m$ & $h$ & {$[0.2,0.3]$} & 1 \\
\hline & $P_{4}$ & {$[200,300]$} & ls & $m$ & {$[1.5,2.5]$} & 1 \\
\hline & $P_{5}$ & {$[50,80]$} & $h s$ & $b t h$ and $v h$ & {$[0.2,0.25]$} & 1 \\
\hline \multirow{5}{*}{$e_{4}$} & $P_{1}$ & {$[25,40]$} & vls & $v l$ & {$[0.2,0.25]$} & 1 \\
\hline & $P_{2}$ & {$[30,45]$} & vls & At most $l$ & {$[0.4,0.5]$} & 1 \\
\hline & $P_{3}$ & {$[80,150]$} & ls & $m$ & {$[0.6,1.0]$} & 1 \\
\hline & $P_{4}$ & {$[200,250]$} & $b t l s$ and $m$ & $l$ & {$[1.5,3.0]$} & 1 \\
\hline & $P_{5}$ & {$[50,70]$} & vhs & vh & {$[0.3,0.6]$} & 1 \\
\hline \multirow{5}{*}{$e_{5}$} & $P_{1}$ & {$[20,30]$} & vls & $l$ & {$[0.25,0.3]$} & 1 \\
\hline & $P_{2}$ & {$[30,40]$} & ls & $v l$ & {$[0.3,0.4]$} & 1 \\
\hline & $P_{3}$ & {$[50,80]$} & At most $m$ & $m$ & {$[0.5,1.0]$} & 1 \\
\hline & $P_{4}$ & {$[150,300]$} & $v l s$ & $l$ & {$[2.0,2.5]$} & 1 \\
\hline & $P_{5}$ & {$[40,70]$} & $b t h s$ and whs & wh & {$[0.35,0.5]$} & 1 \\
\hline \multirow{5}{*}{$e_{6}$} & $P_{1}$ & {$[30,40]$} & ls & $v l$ & {$[0.2,0.3]$} & 1 \\
\hline & $P_{2}$ & {$[20,50]$} & vls & $v l$ & {$[0.5,0.6]$} & 1 \\
\hline & $P_{3}$ & {$[40,70]$} & ls & $l$ & {$[0.4,0.6]$} & 1 \\
\hline & $P_{4}$ & {$[200,300]$} & $m$ & $b t v l$ and $l$ & {$[2.5,3.5]$} & 1 \\
\hline & $P_{5}$ & {$[50,60]$} & hs & $h$ & {$[0.3,0.5]$} & 1 \\
\hline
\end{tabular}

Table 6. The importance of each criterion provided by each expert.

\begin{tabular}{cccccc}
\hline \multirow{2}{*}{ Experts } & \multicolumn{5}{c}{ Criteria } \\
\cline { 2 - 6 } & $C_{\mathbf{1}}$ & $C_{\mathbf{2}}$ & $C_{\mathbf{3}}$ & $C_{\mathbf{4}}$ & $C_{\mathbf{5}}$ \\
\hline$e_{1}$ & vhi & $h i$ & $h i$ & $l i$ & $m i$ \\
$e_{2}$ & $b$ thi and $v h i$ & $h i$ & $h i$ & $m i$ & $l i$ \\
$e_{3}$ & $h i$ & $m i$ & $h i$ & $l i$ & $v l i$ \\
$e_{4}$ & $v h i$ & $m i$ & $m i$ & $l i$ & $v l i$ \\
$e_{5}$ & $h i$ & $m i$ & $h i$ & $m i$ & $l i$ \\
$e_{6}$ & At least $h i$ & $h i$ & $h i$ & $m i$ & $l i$ \\
\hline
\end{tabular}

Note: "bt" means between in Tables 5 and 6 .

Table 7. The familiarity degree provided by all experts for each criterion.

\begin{tabular}{cccccc}
\hline \multirow{2}{*}{ Experts } & \multicolumn{5}{c}{ Criteria } \\
\cline { 2 - 6 } & $\boldsymbol{C}_{\mathbf{1}}$ & $\boldsymbol{C}_{\mathbf{2}}$ & $\boldsymbol{C}_{\mathbf{3}}$ & $\boldsymbol{C}_{\mathbf{4}}$ & $\boldsymbol{C}_{\mathbf{5}}$ \\
\hline$e_{1}$ & $v s$ & $s$ & $v s$ & $m$ & $m$ \\
$e_{2}$ & $s$ & $m$ & $s$ & $v s$ & $m$ \\
$e_{3}$ & $m$ & $v s$ & $v s$ & $m$ & $s$ \\
$e_{4}$ & $v s$ & $m$ & $s$ & $s$ & $m$ \\
$e_{5}$ & $m$ & $v s$ & $v s$ & $s$ & $u$ \\
$e_{6}$ & $s$ & $s$ & $s$ & $m$ & $m$ \\
\hline
\end{tabular}




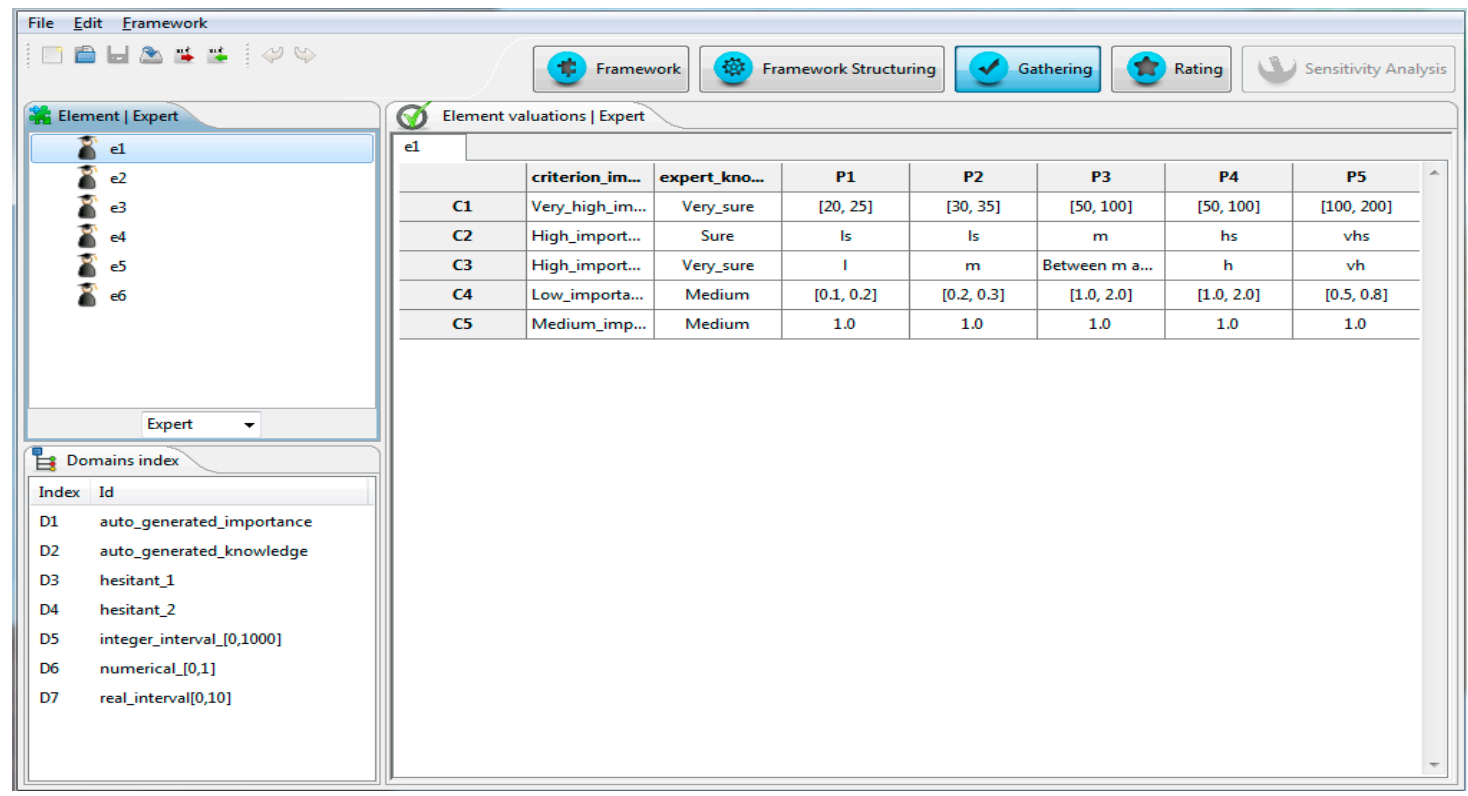

Figure 8. Gathered information in GENESIS.

\subsubsection{Managing Non-Homogeneous Information}

All experts' assessments are transformed into trapezoidal fuzzy numbers by utilizing the transformation functions defined in Section 3.2. Therefore, GENESIS makes all the necessary computations to unify the non-homogeneous information into a fuzzy domain in a simple and fast way. Figure 9 shows the interface of such a process.

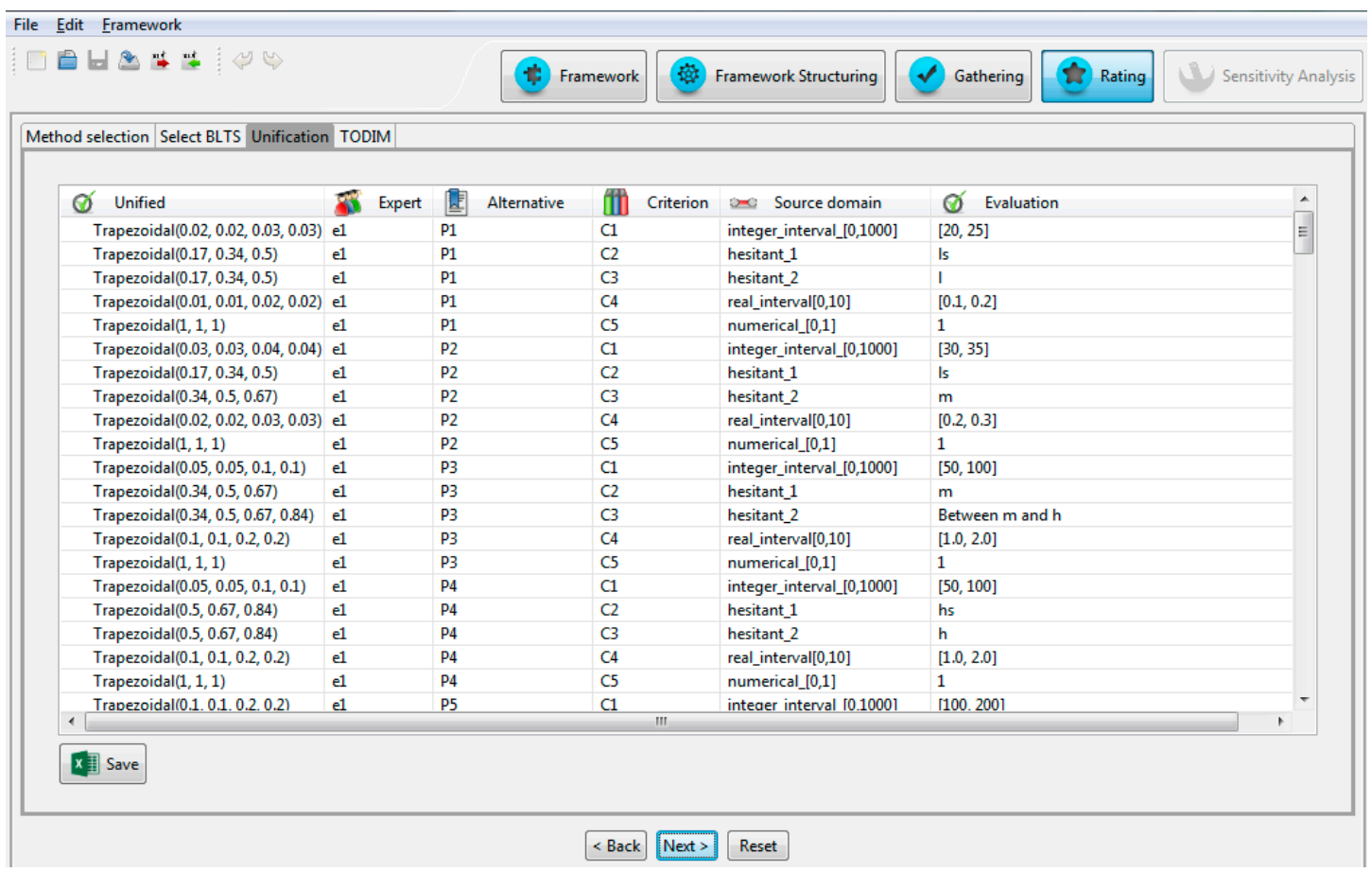

Figure 9. Unification results of non-homogeneous information. 


\subsubsection{Consensus Reaching Process}

The fuzzy linear programming-based consensus model is utilized to achieve the consensus among all experts involved in the GEDM problem and obtain the collective opinion that will be used in the selection process. Before applying the CRP, the threshold values in Equation (14) should be determined.

Let $S_{4}=\left\{s_{0}\right.$ : none $(n), s_{1}$ : very unsure $(v u), s_{2}$ : unsure $(u), s_{3}$ : medium $(m), s_{4}:$ sure $(s), s_{5}$ : very sure (vs), $s_{6}$ : absolutely sure (as)\} be the linguistic term set (see Figure 10) used by experts to express their familiarity degree for each criterion.

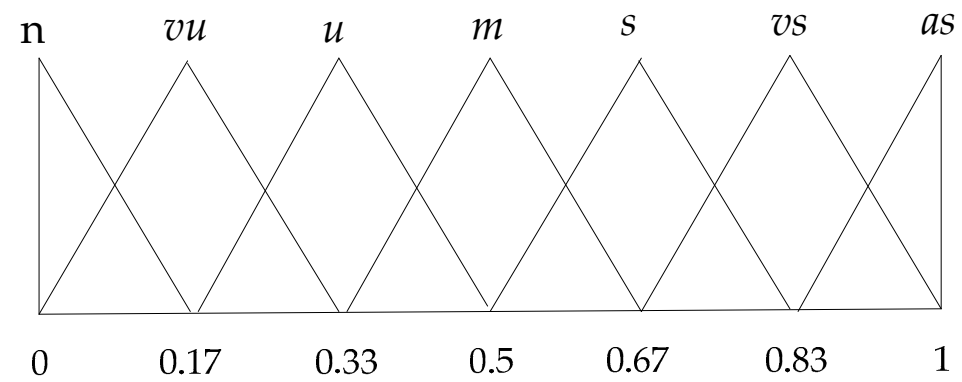

Figure 10. Linguistic term set $S_{4}$.

Expert $e_{h}$ provides his/her familiarity degree for the criterion $c_{j}$ by using a linguistic term $s_{k} \in S_{4}$. According to Equation (16), $\widetilde{s}_{q}=s_{6-k}$, then, the COG of $\widetilde{s}_{q}$ is regarded as the threshold value for the expert $e_{h}$ about the criterion $c_{j}$, shown in Table 8 . Table 7 is the familiarity degree provided by all experts for each criterion.

Table 8. Threshold values for $\widetilde{s}_{q}$ transformed by negative operator.

\begin{tabular}{cc}
\hline$\widetilde{s}_{\boldsymbol{q}}$ & Threshold Value \\
\hline$\widetilde{s}_{0}$ & 0 \\
$\widetilde{s}_{1}$ & 0.17 \\
$\widetilde{s}_{2}$ & 0.33 \\
$\widetilde{s}_{3}$ & 0.5 \\
$\widetilde{s}_{4}$ & 0.67 \\
$\widetilde{s}_{5}$ & 0.83 \\
$\widetilde{s}_{6}$ & 1 \\
\hline
\end{tabular}

For example, expert $e_{1}$ provides his/her familiarity degree for the criterion $c_{1}, s_{5}=v s$, then according to Equation (16), $\widetilde{s}_{1}=v u$, and, the COG of $\widetilde{s}_{1}$ is 0.17 , i.e., $\varepsilon_{1}^{1}=\operatorname{COG}(v u)=0.17$, it means that the maximum change that expert $e_{1}$ can make is 0.17 for the criterion $c_{1}$.

In this GEDM problem, experts' weights $w^{h}$ have the same importance. The parameters $p, \alpha$ and $c$ used in Equation (13) are set, $p=2, \alpha=2$ and $c=1.5$ respectively [36].

When all constraints meet the conditions in Equation (14), the aggregated collective opinion, $\mathrm{CO}=\left(\mathrm{CO}_{i j}\right)_{5 \times 5}$, is obtained.

$C O=\left[\begin{array}{cccccc}(0.02,0.02,0.04,0.04) & (0.11,0.22,0.22,0.41) & (0.11,0.22,0.22,0.49) & (0.02,0.02,0.03,0.03) & (1,1,1,1) \\ (0.03,0.03,0.08,0.08) & (0.14,0.19,0.19,0.60) & (0.11,0.17,0.17,0.44) & (0.04,0.04,0.06,0.06) & (1,1,1,1) \\ (0.07,0.07,0.28,0.28) & (0.18,0.30,0.32,0.53) & (0.21,0.37,0.37,0.79) & (0.06,0.06,0.25,0.25) & (1,1,1,1) \\ (0.17,0.17,0.50,0.50) & (0.20,0.38,0.38,0.69) & (0.15,0.30,0.33,0.62) & (0.23,0.23,0.40,0.40) & (1,1,1,1) \\ (0.05,0.05,0.09,0.09) & (0.53,0.70,0.70,0.90) & (0.58,0.73,0.73,0.95) & (0.02,0.02,0.05,0.05) & (1,1,1,1)\end{array}\right]$

\subsubsection{Calculation of Criteria Weights}

Using Table 6, the criteria weights are calculated by GENESIS (see Figure 11). 


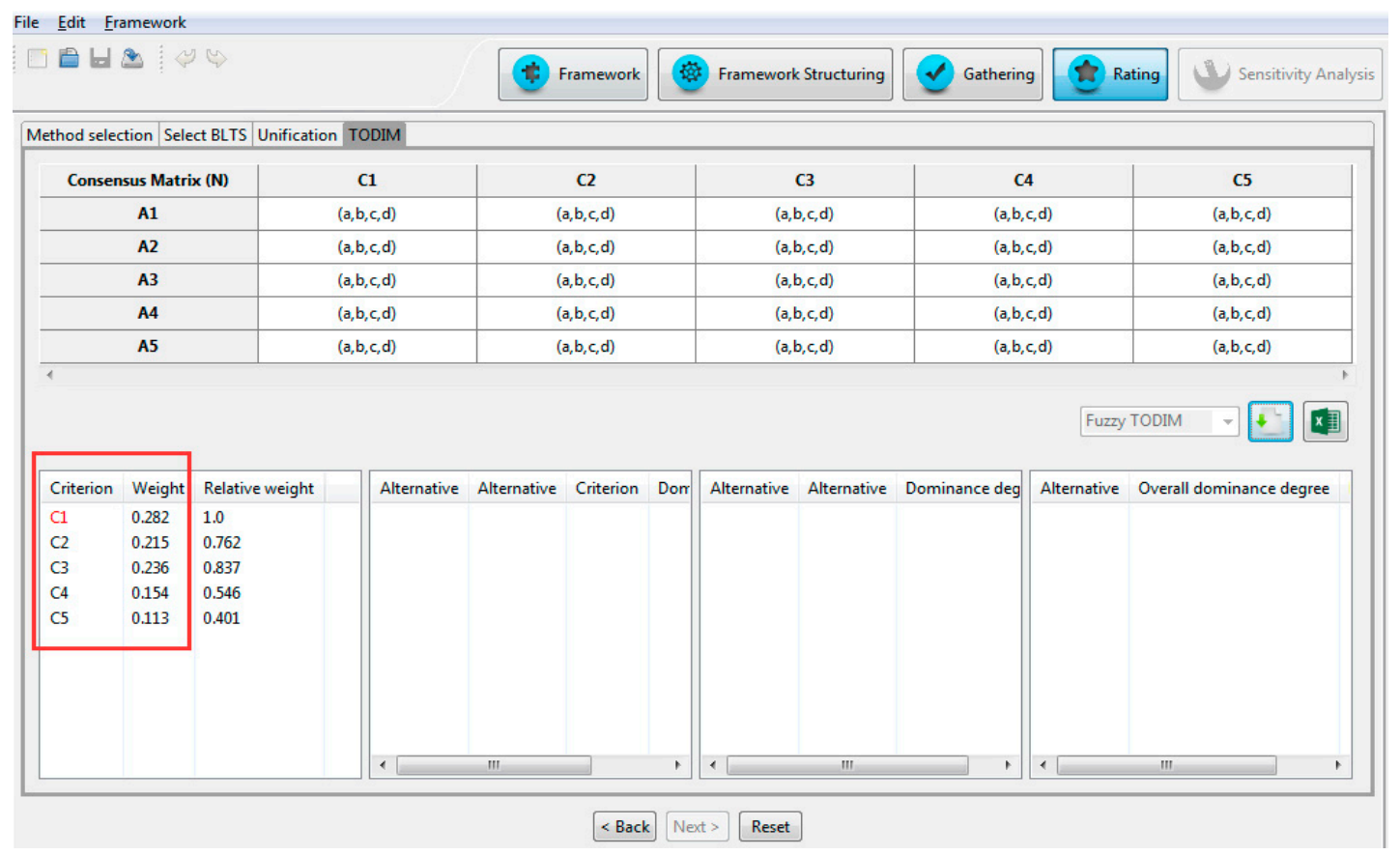

Figure 11. Criteria weights $w_{c_{j}}$ obtained by GENESIS.

\subsubsection{Selection Process-Fuzzy TODIM Method}

Once the criteria weights $w_{c_{j}}$ and the aggregated collective opinion $C O=\left(C O_{i j}\right)_{m \times n}$ are obtained, fuzzy TODIM method is applied to calculate the overall dominance degree for each alternative and then the ranking of the alternative is obtained. Figure 12 shows the results obtained for each step of the fuzzy TODIM method.

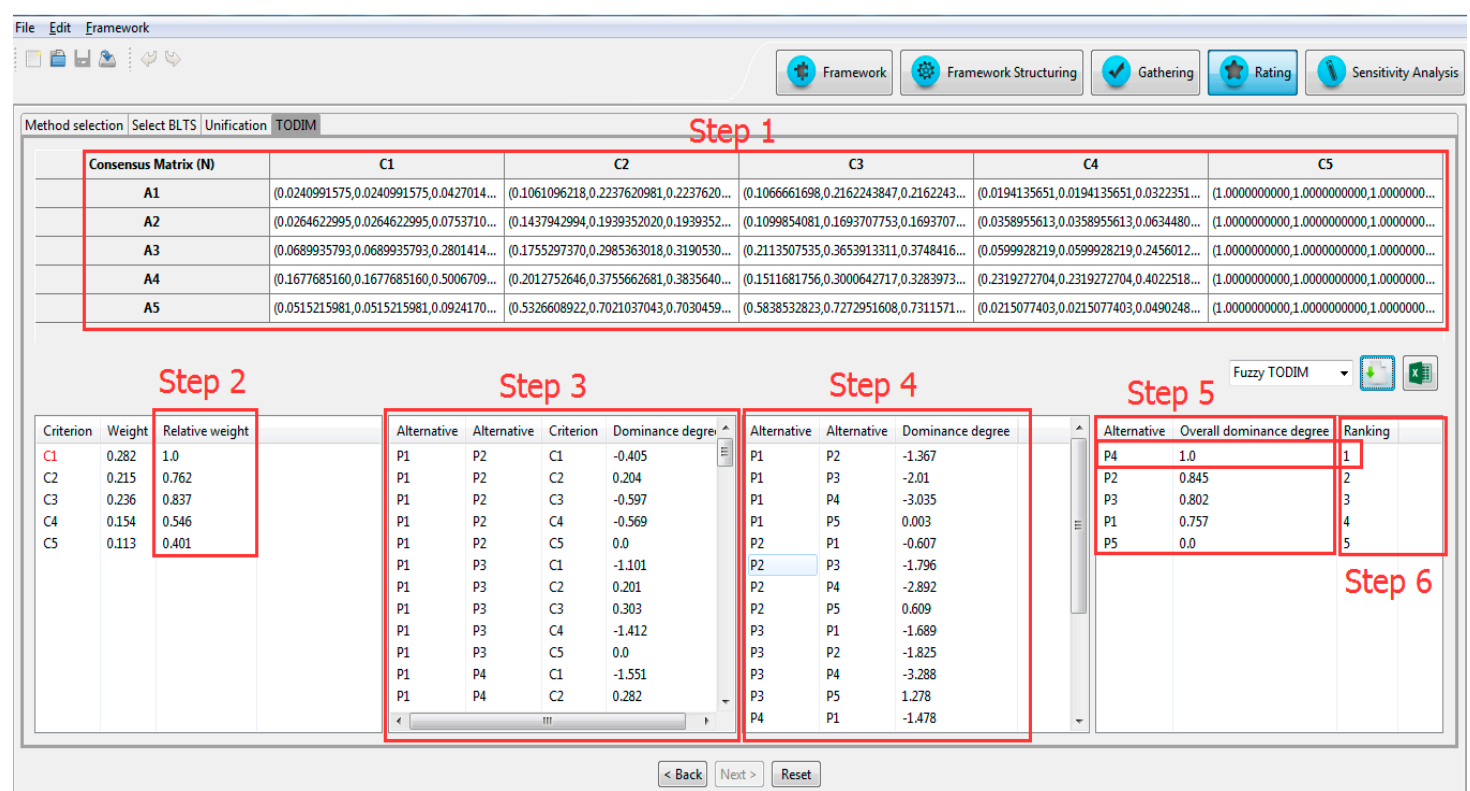

Figure 12. The results of different steps based on fuzzy TODIM by using GENESIS. 
The ranking of alternatives is obtained according to the overall dominance degree for each alternative:

$$
p_{4} \succ p_{2} \succ p_{3} \succ p_{1} \succ p_{5}
$$

Finally, the EM can select $p_{4}$, "joint rescue" as the best alternative for the emergency response.

\subsubsection{Sensitivity Analysis}

To illustrate the feasibility and validity of the proposed method, sensitivity analysis is carried out in a similar way to other TODIM-based proposals in literature [38].

In this case, two aspects of sensitivity analysis are conducted: (i) the analysis about the weight evolution of the most important criterion and (ii) the evolution of attenuation factor $\theta$.

For the weight evolution of the most important criterion, in this case study, it is $C_{1}$. First, let the weight of criterion $C_{1}$ be equal to the second most important criterion, i.e., $C_{1}=0.236$, then changing the weight of $C_{1}$ from 0.236 to 1 . The reason for doing this is that the most important criterion is always the same and never changes, hence the relative weights are always calculated according to the same criterion. Applying these changes, the ranking of alternatives does not change.

The attenuation factor $\theta$ evolution, is changed from 1 to 15 . When these alterations are carried out, there is no any change in the ranking of alternatives.

From the sensitivity analysis, it is easy to see that the ranking of alternatives is consistent with each other. It shows the feasibility, validity and the robustness of the proposed method.

\section{Conclusions and Future Works}

The non-homogeneous information including experts' hesitancy is not available in current GEDM approaches. To fill such a gap, this paper has taken into account the non-homogeneous information including experts' hesitancy, which extends the scope of non-homogeneous information defined in previous approaches. In order to make computations with non-homogeneous information defined in our proposal, different transformation functions have been presented to unify it into fuzzy numbers. A fuzzy linear programming-based consensus model with a new way for determining the threshold values has been applied to obtain the collective opinion, which is suitable for dealing with the fuzzy information. Experts' psychological behavior is very important in decision processes under risk and uncertainty; however, it is neglected in current GEDM approaches. To address such an important issue, fuzzy TODIM method has been utilized in our proposal due to its advantage of capturing human beings psychological behavior. Furthermore, a case study has been provided to illustrate the feasibility and validity of the proposed method by using GENESIS supporting the whole decision process.

Future research could be the use of computer science and Internet technology for supporting the EDM based on big data, which will lead to more reliable decisions. Furthermore, game theory [47,48] can be applied to deal with the emergency problems under uncertainty.

Acknowledgments: This work was partly supported by the Young Doctoral Dissertation Project of Social Science Planning Project of Fujian Province (Project No. FJ2016C202), National Natural Science Foundation of China (Project Nos. 71371053, 61773123), Spanish National Research Project (Project No. TIN2015-66524-P), and Spanish Ministry of Economy and Finance Postdoctoral Fellow (IJCI-2015-23715) and ERDF.

Author Contributions: All authors have contributed equally to this paper.

Conflicts of Interest: The authors declare no conflict of interest.

\section{References}

1. Levy, J.K.; Taji, K. Group decision support for hazards planning and emergency management: A group analytic network process (GANP) approach. Math. Comput. Model. Int. J. 2007, 46, 906-917. [CrossRef]

2. Liu, Y.; Fan, Z.P.; Zhang, Y. Risk decision analysis in emergency response: A method based on cumulative prospect theory. Comput. Oper. Res. 2014, 42, 75-82. [CrossRef] 
3. Wang, L.; Zhang, Z.X.; Wang, Y.M. A prospect theory-based interval dynamic reference point method for emergency decision making. Expert Syst. Appl. 2015, 42, 9379-9388. [CrossRef]

4. Xu, X.H.; Du, Z.J.; Chen, X.H. Consensus model for multi-criteria large-group emergency decision making considering non-cooperative behaviors and minority opinions. Decis. Support Syst. 2015, 79, 150-160. [CrossRef]

5. Xu, Y.; Zhang, W.; Wang, H. A conflict-eliminating approach for emergency group decision of unconventional incidents. Knowl. Based Syst. 2015, 83, 92-104. [CrossRef]

6. Ju, Y.; Wang, A.; Liu, X. Evaluating emergency response capacity by fuzzy AHP and 2-tuple fuzzy linguistic approach. Expert Syst. Appl. 2012, 39, 6972-6981. [CrossRef]

7. Herrera, F.; Herrera-Viedma, E.; Verdegay, J.L. A sequential selection process in group decision making with a linguistic assessment approach. Inf. Sci. 1995, 85, 223-239. [CrossRef]

8. Roubens, M. Fuzzy sets and decision analysis. Fuzzy Sets Syst. 1997, 90, 199-206. [CrossRef]

9. Butler, C.L.; Rothstein, A. On Conflict and Consensus: A Handbook on Formal Consensus Decision Making, 2nd ed.; Citeseer: Food Not Bombs Publishing: Portland, ME, USA, 2007; pp. 21-22.

10. Saint, S.; Lawson, J.R. Rules for Reaching Consensus: A Modern Approach to Decision Making; Jossey-Bass: San Francisco, CA, USA, 1994; pp. 27-49.

11. Ping, F.; Chong, W.; Jie, T. Unconventional emergency management based on intelligent group decision-making methodology. Adv. Inf. Sci. Serv. Sci. 2012, 4, 208-216.

12. Camerer, C. Bounded rationality in individual decision making. Exp. Econ. 1998, 1, 163-183. [CrossRef]

13. Tversky, A.; Kahneman, D. Advances in prospect theory: Cumulative representation of uncertainty. J. Risk Uncertain. 1992, 5, 297-323. [CrossRef]

14. Kahneman, D.; Tversky, A. Prospect theory: An analysis of decision under risk. Econometrica 1979, 47, 263-291. [CrossRef]

15. Yu, L.; Lai, K.K. A distance-based group decision-making methodology for multi-person multi-criteria emergency decision support. Decis. Support Syst. 2011, 51, 307-315. [CrossRef]

16. Wei, C.; Ren, Z.; Rodriguez, R.M. A hesitant fuzzy linguistic TODIM method based on a score function. Int. J. Comput. Intell. Syst. 2015, 8, 701-712. [CrossRef]

17. Tosun, Ö.; Akyüz, G. A fuzzy TODIM approach for the supplier selection problem. Int. J. Comput. Intell. Syst. 2015, 8, 317-329. [CrossRef]

18. Krohling, R.A.; Souza, T.T. Combining prospect theory and fuzzy numbers to multi-criteria decision making. Expert Syst. Appl. 2012, 39, 11487-11493. [CrossRef]

19. Estrella, F.J.; Espinilla, M.; Herrera, F.; Martínez, L. Flintstones: A fuzzy linguistic decision tools enhancement suite based on the 2-tuple linguistic model and extensions. Inf. Sci. 2014, 280, 152-170. [CrossRef]

20. Martínez, L.; Rodriguez, R.M.; Herrera, F. Flintstones: A Fuzzy Linguistic Decision Tools Enhancement Suite. In The 2-Tuple Linguistic Model; Springer: Cham, Switzerland, 2015; pp. 145-168.

21. Palomares, I.; Rodríguez, R.M.; Martínez, L. An attitude-driven web consensus support system for heterogeneous group decision making. Expert Syst. Appl. 2013, 40, 139-149. [CrossRef]

22. Cabrerizo, F.J.; Herrera-Viedma, E.; Pedrycz, W. A method based on PSO and granular computing of linguistic information to solve group decision making problems defined in heterogeneous contexts. Eur. J. Oper. Res. 2013, 230, 624-633. [CrossRef]

23. Herrera, F.; Martínez, L.; Sánchez, P.J. Managing non-homogeneous information in group decision making. Eur. J. Oper. Res. 2005, 166, 115-132. [CrossRef]

24. Peng, D.H.; Gao, C.Y.; Zhai, L.L. Multi-criteria group decision making with heterogeneous information based on ideal points concept. Int. J. Comput. Intell. Syst. 2013, 6, 616-625. [CrossRef]

25. Li, D.F.; Huang, Z.G.; Chen, G.H. A systematic approach to heterogeneous multiattribute group decision making. Comput. Ind. Eng. 2010, 59, 561-572. [CrossRef]

26. Zhang, G.; Lu, J. An integrated group decision-making method dealing with fuzzy preferences for alternatives and individual judgments for selection criteria. Group Decis. Negot. 2003, 12, 501-515. [CrossRef]

27. Estrella, F.J.; Cevik Onar, S.; Rodríguez, R.M.; Basar, O.; Luis, M.; Cengiz, K. Selecting firms in university technoparks: A hesitant linguistic fuzzy TOPSIS model for heterogeneous contexts. J. Intell. Fuzzy Syst. 2017, 2, 1155-1172. [CrossRef]

28. Rodríguez, R.M.; Labella, A.; Martínez, L. An overview on fuzzy modelling of complex linguistic preferences in decision making. Int. J. Comput. Intell. Syst. 2016, 9, 81-94. [CrossRef] 
29. Rodríguez, R.M.; Martínez, L.; Herrera, F. Hesitant fuzzy linguistic term sets for decision making. IEEE Trans. Fuzzy Syst. 2012, 20, 109-119. [CrossRef]

30. Rodríguez, R.M.; Martínez, L.; Herrera, F. A group decision making model dealing with comparative linguistic expressions based on hesitant fuzzy linguistic term sets. Inf. Sci. 2013, 241, 28-42. [CrossRef]

31. Quesada, F.J.; Palomares, I.; Martínez, L. Managing experts behavior in large-scale consensus reaching processes with uninorm aggregation operators. Appl. Soft Comput. 2015, 35, 873-887. [CrossRef]

32. Dong, Y.; Luo, N.; Liang, H. Consensus building in multiperson decision making with heterogeneous preference representation structures: A perspective based on prospect theory. Appl. Soft Comput. 2015, 35, 898-910. [CrossRef]

33. Palomares, I.; Estrella, F.J.; Martínez, L.; Herrera, F. Consensus under a fuzzy context: Taxonomy, analysis framework afryca and experimental case of study. Inf. Fusion 2014, 20, 252-271. [CrossRef]

34. Liu, J.; Chan, F.T.; Li, Y.; Zhang, Y.; Deng, Y. A new optimal consensus method with minimum cost in fuzzy group decision. Knowl. Based Syst. 2012, 35, 357-360. [CrossRef]

35. Lee, H.S. Optimal consensus of fuzzy opinions under group decision making environment. Fuzzy Sets Syst. 2002, 132, 303-315. [CrossRef]

36. Gomes, L.; Lima, M. From modeling individual preferences to multicriteria ranking of discrete alternatives: A look at prospect theory and the additive difference model. Found. Comput. Decis. Sci. 1992, 17, 171-184.

37. Gomes, L.; Lima, M. TODIM: Basics and application to multicriteria ranking of projects with environmental impacts. Found. Comput. Decis. Sci. 1992, 16, 113-127.

38. Gomes, L. An application of the TODIM method to the multicriteria rental evaluation of residential properties. Eur. J. Oper. Res. 2009, 193, 204-211. [CrossRef]

39. Pereira, J.; Gomes, L.F.A.M.; Paredes, F. Robustness analysis in a TODIM-based multicriteria evaluation model of rental properties. Technol. Econ. Dev. Ecol. 2013, 19, 176-190. [CrossRef]

40. Wang, L.; Wang, Y.M.; Martinez, L. A group decision method based on prospect theory for emergency situations. Inf. Sci. 2017, 418-419, 119-135. [CrossRef]

41. Liu, H.; Rodríguez, R.M. A fuzzy envelope for hesitant fuzzy linguistic term set and its application to multicriteria decision making. Inf. Sci. 2014, 258, 220-238. [CrossRef]

42. Chen, S.J.; Chen, S.M. Fuzzy risk analysis based on similarity measures of generalized fuzzy numbers. IEEE Trans. Fuzzy Syst. 2003, 11, 45-56. [CrossRef]

43. Zadeh, L.A. Similarity relations and fuzzy orderings. Inf. Sci. 1971, 3, 177-200. [CrossRef]

44. Zadeh, L.A. Outline of a new approach to the analysis of complex systems and decision processes. IEEE Trans. Syst. Man Cybern. 1973, SMC-3, 28-44. [CrossRef]

45. Mahdavi, I.; Mahdavi-Amiri, N.; Heidarzade, A.; Nourifara, R. Designing a model of fuzzy TOPSIS in multiple criteria decision making. Appl. Math. Comput. 2008, 206, 607-617. [CrossRef]

46. Eclipse Foundation. Available online: http://www.eclipse.org (accessed on 18 April 2016).

47. Zheng, X.; Cheng, Y. Modeling cooperative and competitive behaviors in emergency evacuation: A game-theoretical approach. Comput. Math. Appl. 2011, 62, 4627-4634. [CrossRef]

48. Arena, P.; Fazzino, S.; Fortuna, L.; Maniscalco, P. Game theory and non-liner dynamic: The parrondo paradox case study. Chaos Solitons Fract. 2003, 17, 545-555. [CrossRef]

(C) 2017 by the authors. Licensee MDPI, Basel, Switzerland. This article is an open access article distributed under the terms and conditions of the Creative Commons Attribution (CC BY) license (http://creativecommons.org/licenses/by/4.0/). 